Revistade
Economild
Contemporâned

\title{
DINÂMICA AGRÁRIA, INSTITUIÇÕES E GOVERNANÇA TERRITORIAL PARA O DESENVOLVIMENTO SUSTENTÁVEL DA AMAZÔNIA
}

\author{
Francisco de Assis Costa ${ }^{a}$ \\ Danilo Araújo Fernandes ${ }^{b}$ \\ aProfessor e Pesquisador do Núcleo de Altos Estudos Amazônicos e do Programa de Pós-graduação em \\ Economia da Universidade Federal do Pará. \\ 'Professor e Pesquisador do Núcleo de Altos Estudos Amazônicos e do Programa de Pós-graduação em \\ Economia da Universidade Federal do Pará.
}

Artigo recebido em 23/10/2015 e aprovado em 02/12/2016.

RESUMO: Tendo a referência do debate institucionalista, o artigo discute arranjos institucionais na Amazônia considerando a diversidade estrutural que caracteriza o setor rural na Região. A partir dos diferentes padrões de relações entre trajetórias tecnológicas, estabelece duas grandes configurações representativas das condições de desenvolvimento: i) das economias rurais baseadas em pecuária e agricultura e ii) das economias baseadas em sistemas agroflorestais. Comparando os resultados dos censos agropecuários de 1995 e 2006, o artigo demonstra, para cada caso, as mudanças estruturais ocorridas no período e analisa os ritmos, fundamentos e impactos do crescimento. Especial atenção é dada às bases institucionais dos processos. Como resultado se apresentam dois grandes arranjos institucionais, um que tem no "mercado de terras", outro que tem nas regras de acesso a recursos comuns de biomas e ecossistemas, respectivamente, seu fundamento central. Mecanismos institucionais formais funcionam, em cada território, em interação com essas instituições informais, caracterizando a governança territorial prevalecente. Uma implicação prática indicada, à guisa de conclusão, é a de que políticas para um desenvolvimento com atributo de sustentabilidade devem considerar seriamente essas distinções.

PALAVRAS-CHAVE: governança territorial; instituições na Amazônia; trajetórias tecnológicas rurais na Amazônia; mercado de terras; arranjos institucionais na Amazônia.

CLASSIFICAÇÃO JEL: O17; P48; R11; R14.

Correspondência para: Francisco de Assis Costa

Contato: francisco_de_assis_costa@yahoo.com.br 


\title{
AGRARIAN DYNAMICS, INSTITUTIONS AND TERRITORIAL GOVERNANCE FOR THESUSTAINABLE DEVELOPMENT OF THE AMAZON
}

\begin{abstract}
Referring to the Institutionalist debate in economics, the article discusses institutional arrangements in the Amazon taking into account the structural diversity that characterizes the rural sector in the region. Based on the different patterns of relationships between technological trajectories, two large representative configurations of development conditions are established: i) rural economies based on agriculture and livestock, and ii) economies based on agroforestry systems. Comparing the results of agricultural censuses of 1995 and 2006 one finds, for each case, structural changes in the period and speed, fundamentals and impacts of growth are analyzed. Special attention is given to the institutional foundations of the processes. As a result, two large institutional arrangements are presented, one that has the "land market", and another that has the rules of access to common resources of biomes and ecosystems as its core foundation. Formal institutional mechanisms operate in each territory and interact with these informal institutions, and that characterizes the prevailing territorial governance. As a conclusion, it is found that a practical implication of it is that development policies based on sustainability should seriously consider these distinctions.
\end{abstract}

KEYWORDS: territorial governance; institutions in the Amazon; rural technological trajectory in the Amazon; land market in the Amazon; institutional arrangements. 


\section{INTRODUÇÃO}

A observação da dinâmica agrária da Amazônia tem-se feito privilegiando duas frestas fenomenológicas. Uma reduz a dimensão técnica do processo - em última instância, as mediações que conformam as relações produtivas entre vontade humana socializada e natureza - à oposição desmatamento versus não desmatamento; enquanto a outra realça, em sua dimensão social, o fenômeno da pobreza (COSTA, 2012a, p.245). A par disso, a hipótese de que os dois fenômenos são diretamente correlacionados, sendo o desmatamento um dos resultados de uma armadilha da pobreza (DINIZ et al., 2008): porque empobrecidos em dado contexto, agentes demandam novas áreas cuja exploração requer a supressão do bioma; desprotegida, a terra nua logo empobrece e, com ela, os agentes que a exploraram. Ao fim, os dois fenômenos retroalimentar-se-iam, gestando um futuro de carências sociais e devastação ambiental.

Pesquisas importantes patrocinadas pelo Banco Mundial, observando a região por esses mesmos prismas, diagnosticaram a dinâmica rural amazônica, produzindo três teses. A primeira sustenta que, na região, a agricultura em geral seria uma impossibilidade; eis que seus sistemas constituir-se-iam em usos insustentáveis da base natural, só justificáveis para agentes com baixo custo de oportunidade em outras regiões, que formariam uma fronteira especulativa, sempre em movimento (CHOMITZ e THOMAS, 2000; SCHNEIDER, 1995). Margulis (2003) prossegue, acatando a anterior e formulando a segunda tese do diagnóstico, a de que dessa fronteira especulativa gerar-se-ia uma fronteira consolidada, economicamente sustentável apenas em áreas com pluviometria intermediária, própria à formação de uma pecuária altamente rentável e profissional. Em áreas de pluviometria muito elevada - condição, aliás, dominante na maior parte da região -, porque a grande pecuária profissional lá não se adapta, nada sobreviveria. Nessas áreas, em virtude da elevada umidade que bloqueia a agropecuária mais eficiente, restariam, após o inexorável fracasso da shifting cultivation, terras abandonadas. Haveria “(...) evidência irrefutável de que muito poucas atividades econômicas são viáveis em áreas de alta pluviometria e que praticamente só a atividade madeireira pode fazer sentido" (MARGULIS, 2003, p.65). A terceira tese se refere às economias baseadas na preservação do bioma, enunciando que as populações que a elas se associam (extrativistas e agroextrativistas) seriam (necessariamente) pobres: a impossibilidade de responder às tensões de mercado por via da intensificação do trabalho por unidade de área, questões logísticas próprias das áreas com alta densidade florestal e assimetrias nas cadeias de produto e valor se encarregariam de garantir tal resultado (DRUMOND, 2002).

Sobre tais bases, conclui-se, o desenvolvimento econômico disporia de poucas chances além da alternativa de uma pecuária intensiva em capital e exploração madei- 
reira, cuja intensificação e amplitude exigem conhecimentos e requisitos institucionais parcamente disponíveis. Desse modo, haveria na Amazônia caso agudo do tradeoff entre crescimento e meio ambiente. Os lineamentos programáticos orientados à sustentabilidade deveriam focar, isto posto, na contenção do desmatamento, tanto por mecanismos de controle quanto por mudanças nos critérios decisórios dos agentes, tornando a maximização de suas funções-utilidade dependente de ponderações entre custos de oportunidade e ganhos compensatórios de renda transferida. Dado que tal política tem potencial de geração de pobreza como decorrência da desmobilização de atividades deletérias, recomendam-se ações paralelas de mitigação.

Esse diagnóstico e suas indicações programáticas continuam influentes entre nossos policy makers, eis que não se vislumbram políticas de fomento do desenvolvimento para a região. No entanto, as referências analíticas do próprio Banco Mundial, subjacentes a seus recentes relatórios na perspectiva do green growth (WORLD BANK, 2012), mudaram notavelmente, na esteira da green economy (UNEP, 2011) sugerida pelas Nações Unidas: ambas as organizações enunciam a necessidade de superar tradeoffs entre crescimento econômico, ganhos ambientais e inclusão social. Urge acumular conhecimento que permita a reflexão e a ação estratégica nessa nova perspectiva. Demonstrar, portanto, possibilidades de desenvolvimento com maior esperança de sustentabilidade e capacidade inclusiva na Amazônia constitui o objetivo deste artigo. Cumprir-se-á tal propósito considerando as condições estruturais e dinâmicas da economia rural da região e os arranjos institucionais que, à guisa de governança territorial, lhe são inerentes.

Na condução de nossos argumentos apresentaremos, na seção 2, as três principais matrizes teóricas sobre instituições e desenvolvimento, a nova economia institucional, a sociologia econômica e a abordagem dos recursos comuns, situando-as em relação à perspectiva do desenvolvimento sustentável e à governança territorial. Na seção 3 exporemos um quadro da dinâmica rural na Amazônia no período entre os censos de 1995 e 2006, destacando a diversidade estrutural, o desempenho variado das diferentes estruturas em movimento, as trajetórias tecnológicas e os papeis correlatos de diferentes configurações institucionais. Por fim, a título de conclusão, faremos uma síntese dos resultados alcançados e indicaremos possibilidades de políticas para o desenvolvimento que considerem os resultados apresentados.

\section{DESENVOLVIMENTO SUSTENTÁVEL E GOVERNANÇA ECONÔMICA-TERRITORIAL: UMA CONVERGÊNCIA NECESSÁRIA}

O conceito de Desenvolvimento Sustentável (DS) - noção que, para a qualificação de um processo de evolução social, articula os atributos de eficiência produtiva com os de 
equidade intra e intergerações, professando o anseio ético de que, com o resultado do esforço produtivo de todos, corrijam-se as desigualdades entre os membros das gerações presentes e garanta-se a igualdade entre estas e as próximas gerações, só possível com a manutenção das condições operantes da base natural - se constitui em ideário, isto é, articulação de valores primários, cuja força ideal, proporcional ao grau de compartilhamento que desfruta na sociedade, orienta a construção das instituições que moldam o devir.

As iniciativas mencionadas na introdução como Economia Verde (EV) e Crescimento Verde (CV) são, chamemos assim, operadores programáticos do ideário do desenvolvimento sustentável, cuja formulação vem exigindo, no interior da disciplina de economia, aproximações entre abordagens neoclássicas (GROSSMAN e KRUEGER, 1991; PEARCE et al., 1989) e uma convergência teórica mais ampla formada por neoschumpeterianos evolucionários (AYRES, 1989 e 2008; KEMP e SOETE, 1992) e autores do desenvolvimento endógeno (PORTER e VAN DER LINDE, 1995a, 1995b).

A categoria-chave nessas aproximações, tangências e, mesmo, convergências, é a de trajetória tecnológica (DOSI, 2006), como aponta Lustosa (2011), em relação a qual outras, como as de lock-in e irreversibilidade são fundamentalmente acionadas em UNEP (2011) e World Bank (2012), com as implicações teóricas necessárias: em todos os casos, o contexto institucional é determinante.

Por caminhos próprios, as pesquisas desenvolvidas no Núcleo de Altos Estudos Amazônicos pelo Grupo de Pesquisa Dinâmica Agrária e Desenvolvimento Sustentável (GPDadesaNAEA), chegaram, antes até, a um ponto semelhante (COSTA, 2009a), ganhando a perspectiva de que a condição decisiva para o desenvolvimento sustentável na Amazônia, a mudança tecnológica, faz-se mediante concorrência de trajetórias tecnológicas (ARTHUR, 1994), emergências que articulam agentes e estruturas em contextos institucionais que desempenham papéis determinantes, seja para garantir o fortalecimento das trajetórias recomendáveis ao desenvolvimento sustentável, agilizando a formação e incorporação das técnicas com isso compatíveis, seja para conter as que operam por meios e técnicas deletérias (COSTA, 2009b). Nessa ótica, o papel da política tem sido decisivo para o status quo, tanto quanto será vital para as mudanças necessárias ao desenvolvimento que, parafraseando a UNEP, produza “(...) uma transição para uma economia verde, eliminando tradeoffs entre crescimento econômico, investimento e ganhos de qualidade ambiental e inclusão social" (UNEP, 2011, p.16).

Os últimos anos constituíram um momento de arremate e síntese desse esforço. Explicitou-se, com maior nitidez, a diversidade de agentes e as estruturas que os abrigam no contexto de diferentes trajetórias tecnológicas que configuram os sistemas agrários presentes; se demonstrou que eram diferentes os impactos entre a dinâmica econômica de cada uma dessas trajetórias e seus fundamentos naturais e sociais: no que se 
refere à dimensão natural, se verificaram as diferenças quanto aos fenômenos de desmatamento, de emissão de $\mathrm{CO}_{2}$ e degradação do solo, se observando trajetórias de alto, de médio e de baixo impacto em todos os quesitos, além de correlação direta entre eles; no que trata a dimensão social, às trajetórias se refere, também, com distinções relevantes, o fenômeno da pobreza. Verificou-se, adicionalmente, que as trajetórias se constituem em importantes vetores de configuração dos arranjos e economias locais, as quais, em cadeias de produto e valor de alcance nacional e mundial, garantem diferentes graus de absorção e diferentes modos de distribuição de resultados entre os protagonistas locais, trabalhadores e empresas. No todo, deram-se passos importantes na demonstração de que, por efeito de composição, os ritmos de crescimento das trajetórias tecnológicas, associadas às estruturações que protagonizam, qualificam o desenvolvimento nas dimensões ecológica, social e econômica (COSTA, 2016, 2013, 2012, 2009b, 2009c).

Cabe-nos, agora, chamar a atenção para a dimensão institucional dos processos de crescimento e desenvolvimento, destacando o papel da governança territorial na orientação da dinâmica das trajetórias do setor rural na Amazônia. Nesse intuito, iniciaremos por revisar noções das teorias contemporâneas sobre governança, que têm sido referências para os debates acadêmicos no campo das teorias do desenvolvimento. $\mathrm{O}$ propósito é estabelecer suas relações com a questão da gestão sustentável dos recursos naturais na Amazônia. Em seguida, coloca-se a questão da sustentabilidade e da dinâmica territorial na Amazônia como objeto de estudo específico. Nesse momento se estabelecerão os termos de uma interpretação mais acurada da dinâmica agrária regional, pondo em relevo a dimensão territorial e a estreita relação que mantém com a noção de governança, indispensável para avaliar as possibilidades de desenvolvimento sustentável na região Amazônica.

\subsection{O CONCEITO DE GOVERNANÇA NO DEBATE TEÓRICO SOBRE DESENVOLVIMENTO E SUSTENTABILIDADE}

\subsubsection{GOVERNANÇA: ARRANJOS INSTITUCIONAIS FORMAIS MEDIADOS PELO ESTADO PARA A BUSCA PELA EFICIÊNCIA DO MERCADO}

O conceito de governança é, como o de sustentabilidade, exemplo de termos que, por causa de seu sucesso como forma de expressão de um determinado problema, ou como expressão de questão relevante em determinado campo social, com o tempo passam a assumir um sentido polifônico e multifacetado. Com efeito, vários são os significados que se pode atribuir hoje em dia ao termo governança no debate acadêmico, no campo das ciências sociais. Na ciência econômica, por exemplo, em aborda- 
gens neo ou novo institucionalista, o termo é tratado dominantemente como sinônimo das regras que organizam o funcionamento dos mercados e das trocas, tendo em vista a busca pela minimização dos custos de transação em um determinado ambiente de negócios (COASE, 1937; WILLIAMSON, 1975, 1979, 1996).

Nessa linha, Douglass North e Robert Thomas (1973), em um importante texto da década de 1970, assinalam um ponto central: "a organização eficiente implica o estabelecimento de arranjos institucionais e direitos de propriedade que criam um incentivo para canalizar o esforço econômico individual para atividades que aproximam as taxas privadas e sociais de retorno" (NORTH e THOMAS, 1973, p.1).

Com tal perspectiva, as análises tidas como neo-institucionalistas se aproximam de uma abordagem social do papel dos custos de transação e das instituições que os regulam, tendo em vista uma melhor compreensão do desenvolvimento das forças de mercado e seus desdobramentos no que se refere às condições históricas que poderiam levar ao processo de crescimento econômico de uma determinada sociedade.

De modo que é a análise do papel do Estado na determinação do direito de propriedade, por meio de regras formais, um dos pontos focais do tratamento dos fundamentos institucionais que determinam a trajetória de desenvolvimento de um país. No entanto, não se trata apenas da garantia do direito de propriedade - por mais que isso seja considerado algo bastante importante; trata-se, ademais, de estabelecer os critérios de definição destes direitos e seus impactos sobre o sistema de incentivo privado. Assim que, para North (1990), as fragilidades que são causa da formação de arranjos institucionais inadequados se devem basicamente ao estímulo à geração de externalidades (positivas e negativas), as quais acabam por se mostrar inadequadas para o desenvolvimento de uma economia e de seus mercados, uma vez que tendem a criar um sistema de incentivos que atua na contramão do crescimento e do desenvolvimento econômico.

Daí deriva a importância dos elementos políticos que influenciam o comportamento econômico estrito senso, os quais também orientam a delimitação do seu campo de análise.

As instituições informais, neste contexto, não obstante consideradas no quadro de uma possível ordem espontânea ${ }^{1}$ (FIANI, 2011), não são compreendidas como capazes de, por si, representar trajetórias autônomas de formação de um ambiente institucional adequado para o desenvolvimento de uma sociedade de mercado em termos mais amplos. Eventualmente, afirma North (1990), em situações isoladas e específicas, instituições comandadas por regras informais podem até ser componente importante;

\footnotetext{
1 Por ordem espontânea entendemos aqui, seguindo Fiani (2011, p. 109), a noção de organização do sistema econômico em que se pressupõe que as relações econômicas se constituiriam e operariam sem a necessidade da intervenção de uma autoridade política externa.
} 
dificilmente, porém, o processo de desenvolvimento econômico em geral poderia se dar sem que um efetivo papel de coordenação seja assumido pelo Estado por meio de suas instituições formais.

Neste ponto, a noção de enforcement e o peso que nela assume o Estado ganham papel destacado em seu modelo; ao Estado caberia a missão, em última instância, de garantir o cumprimento dos contratos e o direito de propriedade definidos por meio das regras formais. O significado de uma governança eficiente voltada para o benefício do desenvolvimento econômico, neste sentido, seria a representação no campo da teoria da nova economia institucional, de um conjunto de regras, garantidas pelo Estado, responsáveis por um sistema de garantias e incentivos favoráveis ao desenvolvimento de iniciativas em prol do crescimento econômico.

\subsubsection{GOVERNANÇA: ARRANJOS INSTITUCIONAIS FORMAIS OU INFORMAIS CONDUZIDOS PELA SOCIEDADE EM TERRITÓRIOS}

A nova economia institucional de Ronald Coase, Oliver Williamson e Douglas North representa esforço de compreensão da mediação institucional na ação econômica individual, em perspectiva que valida o individualismo metodológico, isto é, supõe a centralidade de agentes com razão substantiva, em uma instância à parte da realidade social. Diferentemente disso, a nova sociologia econômica (STEINER, 2006; GRANOVETTER, 1985; GRANOVETTER e SWEDBERGER, 2010) busca um caminho teórico alternativo, no qual se explora o conceito de governança em articulação com o tema do funcionamento dos mercados, estes vistos, porém, em sua condição de instituições inseridas necessariamente em um contexto social, constituídas a partir de determinada configuração espaço-temporal. De modo que, aqui, a territorialidade importa: não se trata de instituições em abstrato, mas de instituições historicamente construídas em delimitações territoriais e imediatas, tal como a elas se referiam os velhos institucionalistas americanos ${ }^{2}$; trata-se, como se reconhece mais recentemente, de compreender a interação entre mercado e dinâmica social pelo ponto de vista da avaliação das redes que se formam em um determinado contexto temporal e espacialmente delimitado; trata-se, por fim, da constituição de campos por atores econômicos, sociais e políticos em articulações estratégicas visando, por um determinado conjunto de procedimentos, resguardados ou não por formalismo organizacional ou legal, a garantia da estabilidade de suas relações em diferentes momentos e campos de atua-

\footnotetext{
2 Por velhos institucionalistas americanos, entendemos aqui a tradição de estudos de Thorstein Weblen, John Commons, Wesley Mitchell e John Galbraith.
} 
ção. A nova sociologia econômica tem início com os trabalhos de Granovetter, na década de 1980. Granovetter incorpora criticamente o conceito de embeddedness (inserção, imersão) utilizado inicialmente por Karl Polanyi (1944), dando a ele um novo sentido teórico. Segundo esta perspectiva, os mercados não são, e, a rigor, nunca foram originalmente, entidades autônomas, como pressupõe a tradição neoclássica. Eles existem em sintonia com um determinado conjunto de instituições que regulam e dão condições de estabilidade para o seu funcionamento. De modo que as instituições não seriam resultados, derivação a posteriori, do funcionamento dos mercados, que se tornariam, com isso, mais eficientes, como na tradição dos economistas neo-institucionalistas, e sim, o próprio fundamento ou condição de existência da organização e do funcionamento dos mercados.

Assim, para a nova sociologia econômica, não existem mercados autônomos: eles são instituições inseridas socialmente por meio de redes de relações sociais ${ }^{3}$. Todo mercado pressupõe alguma institucionalidade que o sustenta do ponto de vista social, político e cultural. A peculiaridade do período liberal clássico do século XIX, por exemplo, só poderia ser explicada pelo desenvolvimento de instituições que garantiram a organização política, econômica e social das sociedades europeias no mesmo período (POLANYI, 1992). À autonomia do mercado, pois, é pressuposta uma organização prévia da sociedade, historicamente determinada, formal ou informalmente estabelecida, que garante o seu funcionamento ao estabelecer o ambiente de governança necessário para o seu "livre" e virtuoso desenvolvimento, inclusive no campo político.

Com tal perspectiva, a discussão institucionalista torna indissociáveis à compreensão dos mercados, e, portanto, da dinâmica econômica, o entendimento dos territórios, destacando como ponto focal os mecanismos de cooperação na construção e constituição dos mercados (ABRAMOVAY, 2007). Trata-se de momento importante a que chega o debate, eis que, como sintetiza Abramovay (2007):

(...) territórios são mais que mercados e envolvem o Estado, suas diferentes agências, os eleitos locais, os vários tipos de organização da sociedade civil, os partidos políticos e o próprio ambiente cultural de uma determinada região. A maneira como os mercados são construídos e como funcionam representa, porém, uma síntese desses diferentes elementos. (ABRAMOVAY, 2007, p.31)

3 O estudo clássico de Granovetter sobre o mercado de trabalho revela, a partir de um estudo empírico, "a influência decisiva dos quadros relacional e institucional nos quais tem lugar a ação econômica" (STEINER, 2006). Por esse ponto de vista, em oposição à obra de Polanyi, Granovetter defende que mesmo nas sociedades modernas, a economia e os mercados não estariam completamente descolados da lógica de reprodução das instituições e das relações sociais. E que as redes sociais teriam importante papel na constituição dos mercados mesmo nas sociedades atuais. 


\subsection{BENS COMUNS, GOVERNANÇA TERRITORIAL E OS ESTUDOS SOBRE O PAPEL DAS INSTITUIÇÕES NA CONSTRUÇÃO DE UM PROJETO DE DESENVOLVIMENTO SUSTENTÁVELPARA A AMAZÔNIA}

Com perspectiva compatível com a nova sociologia econômica, Elinor Ostrom inaugura uma abordagem institucionalista inovadora com foco na gestão do que categoriza com common pool resources (CPR ou simplesmente commons). Os commons combinam os atributos de serem bens de difícil exclusão e alta rivalidade, conforme denominação da ciência econômica (OSTROM, 1994, p.6-7). Um capital natural, isto é, um sistema de recursos naturais que produz fluxos regulares de produtos ou prestam serviços com tais características está submetido aos riscos derivados dos incentivos à sobrexploração.

Na perspectiva de Ostrom (1990), o institucionalismo apoiado em Coase, Williamson e North assumiu três tipos de abordagens no tratamento dos commons: as baseadas na perspectiva da tragédia dos comuns, formulada em 1965 por Garrett Hardin; as que tratam do problema a partir do dilema do prisioneiro, apoiadas na teoria dos jogos e, por fim, as que se baseiam no teorema de Coase sobre o direito de propriedade e a eficiência da gestão privada em situação de baixo custo de transação, como a que formula Olson (1965) na compreensão da lógica da ação coletiva. Para Ostrom, tais formulações apresentam insuficiência teórica e prática.

No plano teórico, as abordagens corroboram uma generalização indevida, porque toda a questão se reduz ao free-rider problem que lhe seria próprio (ORSTROM, 1965, p.6): sempre que uma pessoa não pode ser excluída dos benefícios produzidos por outras, ou por um acervo de recursos pertencentes ao todo social de que faz parte, ela, e cada um dos que compartilham os tais benefícios, é tentada a não contribuir com o esforço comum que garante o acervo e, portanto, os benefícios. Tanto mais isso se verifica, todavia, maior será a subtração de recursos sem compensação, até que nada reste do acervo comum.

No plano prático, derivam das abordagens acima duas possibilidades de contenção da tragédia: a privatização dos recursos ou a intervenção do estado como regulador. A compreensão é de que a exploração se fará sustentável se, e somente se, submetida ou a regras empresariais de monopólio sobre os recursos ou a regras estatais de coordenação das ações interdependentes necessárias ao uso sistemático do recurso. Num caso e no outro, as razões se prendem à apropriação dos rendimentos diferenciais derivados dessas ações, respectivamente, na forma de lucros corporativos ou impostos. A questão fundamental colocada por Ostrom (1990, p.15-17) é a de que falta uma terceira alternativa, na qual os agentes em interação desenham suas próprias regras de ação conjunta para a exploração dos recursos objetivando se apropriarem, eles mesmos, dos 
rendimentos diferenciais resultantes. Assim, nas situações reais, é tão importante distinguir forças que impulsionam à cooperação, quanto as que apelam ao oportunismo.

Nem sempre, reconhece Ostrom (com GARDNER e WALKER, 1994, p.4), os arranjos são bem sucedidos. Mas é certo que em números significativos eles se mostram alternativas com expressões e pesos econômicas demonstrados em múltiplos estudos in field empreendidos em todo o mundo (OSTROM, 1990, p.58-181 e OSTROM, GARDNER e WALKER, 1994, p.225-300). De modo que se faz necessário “o desenvolvimento de uma teoria de auto-organização e governança para esse bem definido universo de problemas e situações" habilitando-nos a "um entendimento dos fatores que podem reforçar ou depreciar a capacidade dos indivíduos de organizar ação coletiva relacionada com a provisão local de bens provenientes de recursos comuns" (OSTROM, 1990, p.27).

Na busca de compreensão sobre "como os indivíduos criam suas próprias instituições, como eles se comprometem a seguir suas próprias regras e, ainda, monitoram uns aos outros na conformação de todas àquelas regras" (ORSTOM, 1990, p.55) a pesquisa de Ostrom procura integrar indivíduos e contextos: agentes e agências; ações e estruturas. Na sua própria formulação:

A estratégia básica é identificar os aspectos físicos, culturais e institucionais que determinam quem deverá estar envolvido em uma situação [de exploração de um CPR], as ações que eles podem empreender, os custos dessas ações e os resultados que delas podem advir (...). (OSTROM, 1990, p.55)

Quanto aos agentes, a autora considera os atributos fundamentais mediante as seguintes indagações: "Os seus interesses são comuns ou heterogêneos? Qual seu horizonte de tempo? Quantos são? Cooperam frequentemente?” (OSTROM, 1990, p.56). Em relação ao contexto, destaca os fundamentos naturais e institucionais. Sobre os primeiros, procura discernir quanto à extensão, à clareza de limites e às qualidades sistêmicas (estrutura interna).

No que se refere às condições institucionais envolvidas, Ostrom (1990, p.51-54) considera, em primeiro lugar, que três conjuntos de instituições e normas interagem como estruturação multinível, condicionando uma situação em foco: regras operacionais seguidas pelos appropriators com suas condições particulares no dia-a-dia da exploração sofrem influência das regras coletivas desenvolvidas pelos appropriators, seus funcionários e autoridades externas que, por sua vez, são afetadas por regras constitucionais que estabelecem elegibilidades, distinguindo quem pode ou não fazer parte do processo de exploração, e conformam regras e mecanismos de garantia das regras coletivas. Em segundo lugar, entende a autora que esses conjuntos de re- 
gras podem atuar, indistintamente, em arenas formais e informais, a depender das situações concretas que, co-determinadas pelas condições naturais (os próprios CPR), são necessariamente referidas a territórios e extraordinariamente diversas (OSTROM, 2005).

\section{DINÂMICA ECONÔMICA, DIVERSIDADE ESTRUTURAL E INSTITUIÇÕES NA AMAZÔNIA}

Vistas as diferentes formas como as abordagens institucionalistas contemporâneas tratam a governança territorial e sua relação com o problema da gestão dos recursos naturais, cabe retomar a discussão sobre dinâmica agrária, desenvolvimento e sustentabilidade na Amazônia, feita na parte introdutória deste texto, chamando a atenção para a dimensão institucional dos processos de crescimento e mudanças. Colocam-se duas questões interrelacionadas: 1) é possível, consideradas as formas como evolui o rural na Amazônia, superar os dilemas que se materializam na região entre crescimento econômico, inclusão social e sustentabilidade ambiental?; e 2) que papeis jogam os arranjos institucionais operantes na Região, as governanças territoriais, na constituição desses dilemas e quais poderão jogar para sua superação?

A análise focará a Região Norte, no período entre os dois últimos censos agropecuários, utilizando primordialmente as bases de dados da versão definitiva do Censo de 2006 acessada em junho de 2015 e do Censo de 1995 disponibilizado em CD pelo IBGE. Em um primeiro momento serão apresentadas as grandes estruturas produtivas (COSTA, 2009) que compõem o agrário da Região Norte, suas características econômicas, sociais e ecológicas. Por essa perspectiva, entende-se que uma diversidade estrutural profunda marca a realidade rural da Região Norte, suas características econômicas, ambientais e sociais. Nessa linha de argumentação, algumas noções têm se mostrado particularmente férteis em explicitar de maneira penetrante e abrangente tal heterogeneidade.

Tem se mostrada eficaz a visão de que, na base da dinâmica da economia rural da Amazônia estão estruturas em movimento, configurando trajetórias que materializam na Região grandes paradigmas tecnológicos (COSTA, 2009). Uma trajetória tecnológica, nessa perspectiva, é um padrão usual de atividades que resolvem, com base em princípios estabelecidos por um paradigma tecnológico, os problemas produtivos e reprodutivos que confrontam os processos decisórios de agentes concretos, em contexto específico, nas dimensões econômica, institucional e social (DOSI, 2006).

A presença imediata da natureza como força produtiva faz a principal diferença entre a produção rural e a indústria. Isto tem tido grande importância no tipo de dinâ- 
mica tecnológica que o desenvolvimento da sociedade capitalista vem produzindo nesses setores. Em nível global, domina um paradigma ou padrão tecnológico, que se afirma por conjuntos de soluções selecionadas pela eficiência demonstrada no controle da natureza para que corresponda às necessidades industriais e capitalistas. Tais soluções se sucedem compondo trajetórias tecnológicas marcadas pela especialização dos sistemas produtivos, pelo uso intensivo da mecânica e da química e pela formação dos sistemas botânicos e biológicos homogêneos para isso necessários.

Tal paradigma "global" está presente na realidade amazônica no universo da produção de bens, controlado pelos agentes produtivos mediante seus critérios próprios de decisão, se camponeses (baseadas em unidades produtivas familiares) ou patronais, e no plano institucional, no universo da gestão das políticas públicas, onde se destacam as relacionadas à terra (mercado de terras e política fundiária, incluindo colonização e reforma agrária), ao capital (política de crédito) e ao conhecimento tecnológico.

Todavia, este paradigma não está sozinho na configuração da realidade rural da Amazônia. Há outras formas de utilização da base natural da Região que pressupõem a manutenção dos princípios sistêmicos da natureza originária e configuram, por isso, um paradigma tecnológico - que tratamos como "paradigma agroextrativista" -, porquanto perspectiva particular do uso social dos recursos e de resolução dos problemas a isso afetos. As soluções daí derivadas organizam trajetórias tecnológicas sobre as quais é necessário discernir. Essas trajetórias, e suas variantes, do mesmo modo que suas concorrentes agropecuárias, dispõem de bases de conhecimento e institucionalidade próprias, dominantemente tácitas e consuetudinárias, fundamente incorporadas na cultura da Região. Tais acervos se constituem de protocolos de acesso (normas) e de uso (técnicas) da natureza originária, no quadro de processos produtivos em que biomas e ecossistemas se reproduzem como capacidade operante (capital natural), co-determinando o resultado do trabalho.

Exercitando essas noções por metodologia já apresentada (COSTA, 2009) chegou-se, utilizando os dados do Censo Agropecuário de 1995, a seis trajetórias tecnológicas em evolução na Amazônia, três camponesas (produção rural de base familiar) e três patronais (empresas e fazendas). Repetindo o exercício para o Censo Agropecuário (versão definitivo) de 2006, se chegou a sete trajetórias tecnológicas: as mesmas seis anteriormente delimitadas e mais uma de base patronal. As características principais dessas estruturações que, como trajetórias tecnológicas, fundamentam a dinâmica da economia rural da Região Norte, estão na Tabela 1. Explicitaremos seus atributos ao tempo em que observaremos seus movimentos no período delimitado, demonstrando as evoluções na organização da produção e seus requisitos econômicos, sociais e técnicos, com atenção destacada nas mediações institucionais. 
Tabela 1 - Diversos atributos das trajetórias tecnológicas rurais na Região Norte (censos de 1995 e 2006)

\begin{tabular}{|c|c|c|c|c|c|c|c|c|c|}
\hline & \multicolumn{3}{|c|}{ Trajetórias Camponesas } & \multicolumn{3}{|c|}{ Trajetórias Patronais } & \multicolumn{3}{|c|}{ Total } \\
\hline & $\mathrm{T} 1(8)$ & T2 (9) & T3 (10) & T4 (11) & T5 (12) & T6 (15) & T7 (14) & $\%$ & Absoluto \\
\hline \multicolumn{10}{|c|}{1995} \\
\hline Tamanho médio (1) & 54 & 23 & 62 & 1.196 & 473 & 413.682 & & & 125,74 ha \\
\hline Pecuária Leite & $39 \%$ & $6 \%$ & $19 \%$ & $32 \%$ & $4 \%$ & $0 \%$ & & $100 \%$ & $\mathrm{R} \$ 1.065 .253 .669$ \\
\hline xt. Madeira & $46 \%$ & $23 \%$ & $4 \%$ & $25 \%$ & $2 \%$ & $0 \%$ & & $100 \%$ & $\mathrm{R} \$ 463.107 .998$ \\
\hline Silvicultura & $1 \%$ & $1 \%$ & $0 \%$ & $1 \%$ & $0 \%$ & $97 \%$ & & $100 \%$ & $\mathrm{R} \$ 181.697 .909$ \\
\hline Cult. Perm. & $49 \%$ & $22 \%$ & $11 \%$ & $6 \%$ & $11 \%$ & $0 \%$ & & $100 \%$ & $\mathrm{R} \$ 1.170 .953 .776$ \\
\hline Cult. Temp. & $31 \%$ & $23 \%$ & $32 \%$ & $13 \%$ & $1 \%$ & $0 \%$ & & $100 \%$ & $\mathrm{R} \$ 2.789 .760 .283$ \\
\hline Prod. da Terra. (R\$) (2) & 526,98 & $1.395,58$ & 381,98 & 129,26 & 303,33 & $2.084,48$ & & & $\mathrm{R} \$ 278,75$ \\
\hline Terra/Trab. (Ha) (3) & 6,35 & 2,02 & 9,44 & 92,86 & 29,84 & 21,17 & & & На 15,74 \\
\hline Produtiv. doTrab. (4) & $3.347,08$ & $2.823,96$ & $3.606,01$ & $12.003,16$ & $9.050,40$ & $44.132,80$ & & & $\mathrm{R} \$ 4.388,79$ \\
\hline Renda Lq. Trab. (5) & $2.789,89$ & $2.578,05$ & $3.096,56$ & $5.320,50$ & $4.591,23$ & $15.022,90$ & & & $\mathrm{R} \$ 3.134,85$ \\
\hline Lucro (6) & $501 \%$ & $1048 \%$ & $608 \%$ & $80 \%$ & $103 \%$ & $52 \%$ & & & \\
\hline IDIC (6) & 0,74 & 0,39 & 0,66 & 1,55 & 3,49 & 0,74 & & & 0,39 \\
\hline Densidade de $\mathrm{CO}_{2}^{8}$ & 0,22 & 0,08 & 0,36 & 1,36 & 0,31 & 0,00 & & & 0,60 \\
\hline Terras degradados & $10 \%$ & $4 \%$ & $14 \%$ & $64 \%$ & $6 \%$ & $2 \%$ & & $100 \%$ & $2.203 .670 \mathrm{Ha}$ \\
\hline \multicolumn{10}{|c|}{2006} \\
\hline Estabelecimentos & 69.568 & 156.728 & 203.544 & 10.115 & 989 & 1.901 & 1.770 & & 444.622 \\
\hline Cult. perm. & $26 \%$ & $42 \%$ & $26 \%$ & $1 \%$ & $4 \%$ & $0 \%$ & $0 \%$ & $100 \%$ & $\mathrm{R} \$ 1.530 .305 .785$ \\
\hline Cult. temp. & $26 \%$ & $35 \%$ & $21 \%$ & $5 \%$ & $1 \%$ & $0 \%$ & $11 \%$ & $100 \%$ & $\mathrm{R} \$ 5.620 .863 .616$ \\
\hline Valor da produção & $17 \%$ & $27 \%$ & $31 \%$ & $14 \%$ & $2 \%$ & $3 \%$ & $6 \%$ & $100 \%$ & $\mathrm{R} \$ 12.900 .522 .256$ \\
\hline Pessoal ocupado & $15 \%$ & $33 \%$ & $40 \%$ & $7 \%$ & $1 \%$ & $3 \%$ & $1 \%$ & $100 \%$ & $1.236 .865 \mathrm{H} / \mathrm{A}$ \\
\hline Total de terras & $8 \%$ & $12 \%$ & $38 \%$ & $23 \%$ & $3 \%$ & $8 \%$ & $7 \%$ & $100 \%$ & $55.535 .777 \mathrm{Ha}$ \\
\hline Prod. da terra. (R\$) (2) & 835,14 & 959,15 & 287,03 & 204,65 & 281,66 & 161,58 & 332,51 & & 374,17 \\
\hline Terra/trab. (Ha) (3) & 13,96 & 8,97 & 28,03 & 98,85 & 135,25 & 63,43 & 155,10 & & 27,88 \\
\hline Produtiv. do trab. (4) & $11.656,04$ & $8.604,48$ & $8.046,07$ & $20.229,37$ & $38.095,12$ & $10.248,54$ & $51.571,65$ & & $10.430,02$ \\
\hline & & & $3.918,63$ & & & & & & \\
\hline \multicolumn{10}{|c|}{ Em $1995 \mathrm{e}$} \\
\hline Renda Lq. trab. (5) & $8.718,68$ & \multicolumn{2}{|c|}{$7.468,492006.918,63$} & $1.454,41$ & $2.162,33$ & $4.099,12$ & $6.611,75$ & & $5.659,10$ \\
\hline Lucro (6) & $297 \%$ & $657 \%$ & $95 \%$ & $8 \%$ & $6 \%$ & $67 \%$ & $15 \%$ & & \\
\hline $\operatorname{IDIC}(6)$ & 0,64 & 0,42 & 1,64 & 1,08 & 1,61 & 0,81 & 0,97 & & 0,64 \\
\hline Densidade de $\mathrm{CO}_{2}^{8}$ & 0,22 & 0,04 & 0,22 & 0,77 & 0,22 & 0,22 & 0,61 & & 0,34 \\
\hline Terras degradados & $7,5 \%$ & $7,7 \%$ & $42,5 \%$ & $28,5 \%$ & $3,4 \%$ & $5,2 \%$ & $5,3 \%$ & $100 \%$ & $2.295 .372 \mathrm{Ha}$ \\
\hline
\end{tabular}

Notas: (1) Total de Terras dos Estabelecimentos/Número de Estabelecimentos. (2) Produtividade Monetária da Terra (PMTr): Valor Bruto da Produção (VBP: Quantidade Produzida vezes Preço Pago ao Produtor)/Área Agricultada Total (AAT: área desmatada utilizada, incluindo pousio. (3) Relação Terra/Trabalho (RTrTb): AAT/TEA.(4) Produtividade Monetária do Trabalho (PMTb): Valor Bruto da Produção (VBP)/Trabalhador Equivalente Ano (TEA), isto é, trabalhadores de diferentes idades e de aplicação temporária ou permanente são transformados em unidades adultas aplicadas em um ano.PMTb = PMTr $\times$ RTrTb. (5) Renda Líquida por Trabalhador (RLTb) = (VBP - Custos)/TEA. Para as empresas camponesas o trabalho familiar não compõe o custo, logo, a RLTb representa o ganho efetivo de cada unidade de trabalho em um ano, um indicador fundamental para decisões. Para as empresas patronais, RLTb é lucro por trabalhador. (6) Taxa Lucro (TXL)= (VBP-Custos)/Custos. Para as empresas patronais, lucro sobre capital adiantado, um indicador fundamental para decisões; nas unidades camponeses, como o trabalho familiar não compõe os custos, a TxL é rendimento líquido do trabalho sobre custo de insumos externos, inclusive eventual trabalho de terceiros. (7) Índice de Densidade Institucional a Partir do Crédito $(I D \mid C)=$ Participação relativa no total de crédito/participação relativa no VBP. (8) Emissão Líquida de CO2NBP. Para o cálculo do balanço de CO2 ver Costa, 2009c e Costa, 2016. (9) Sistemas camponeses de produção que convergem para agricultura mais ou menos especializada. (10) Sistemas agroflorestais. (11) Sistemas camponeses que convergem para pecuária; (12) Sistemas patronais que convergem para a pecuária de corte. (13) Sistemas patronais com plantação de culturas permanentes.(14) Sistemas patronais com silvicultura.(15) Sistemas patronais de culturas temporárias. Fonte: IBGE, Censo Agropecuário 1995 e Censo Agropecuário (definitivo) 2006.

Fonte: Elaboração própria com tabulações especiais dos autores, considerando trajetórias delimitadas de acordo com Costa (2009). 
O período demarcado apresenta importantes mudanças estruturais no setor rural da Região Norte, a par de um crescimento total de $40 \%$ no Valor Bruto da Produção (VBP; para esta e as próximas variáveis, ver notas metodológicas da Tabela 1): o VBP da economia rural da Região Norte registrado no Censo de 2006 foi de R\$12,9 bilhões; no Censo de 1995 o VBP foi de R \$ 9,2 bilhões de reais (todos os valores corrigidos para preços de 2012). A expansão anotada ancorou-se em rendimentos crescentes: a Produtividade Monetária do Trabalho (PMTb) cresceu 137\%, de R $4.378,79$ para $\mathrm{R} \$$ 10.430,02, em parte como resultado do incremento da Produtividade Monetária da Terra (PMTr) em 34\%, de R $\$ 278,75$ para $\mathrm{R} \$ 374,17$ por hectare, em parte por efeito da expansão da Relação Terra-Trabalho (RelTrTb) em 80\%, de 15,74 para 27,88 hectares por Trabalhador Equivalente Ano (TbEq).

No esclarecimento dos fundamentos desse processo de crescimento do setor rural na Região, serão destacados dois conjuntos de eventos estruturais principais que serão discutidos em seguida. Um se dá no contexto de concorrência de trajetórias que tem o protagonismo destacado da Trajetória Tecnológica Patronal T4, composta por estabelecimentos baseados em trabalho assalariado que convergem para a produção especializada de gado para corte, e as relações institucionais que os circunscrevem. Este será o tema a ser tratado na subseção 3.1. O outro conjunto de eventos importantes, no plano estrutural e institucional, ocorre em torno da Trajetória Tecnológica Camponesa T2, que representa os sistemas de produção de empresas fundamentadas em trabalho familiar, para sistemas agroflorestais com alta diversidade de componentes e interações. Sobre isso versará a subseção 3.2. No decorrer da exposição factual e analítica que em seguida se fará, demonstrando a constituição dos arranjos institucionais que prevalece em cada situação, serão apresentadas as características das trajetórias tecnológicas, as tendências de seus fundamentos e suas posições relativas no conjunto do setor rural.

\subsection{DINÂMICA ECONÔMICA E MUTAÇÃO DA T4: CONCORRÊNCIA DE TRAJETÓRIA EM CONTEXTO INSTITUCIONAL DIVERSO E COMPLEXO}

A Trajetória Patronal T4 reunia em 1995 o conjunto de sistemas produtivos operados por 27.831 estabelecimentos patronais que convergiam para a produção de gado em pé: 70\% do VBP de pecuária de corte na Região provinham da T4 (ver Tabela 1). Com estabelecimento médio de 1.196 ha, explicava 28\% do VBP rural da Região Norte e $11 \%$ do total do pessoal ocupado na produção rural. Uma questão em particular ressalta a T4 em relação a todas as demais: em 1995 ela acumulava nada menos que 60\% de todas as terras dos estabelecimentos rurais da Região Norte. Os processos e arranjos que levaram a isso merecem nossa primeira diligência. 


\subsubsection{DINÂMICA FUNDIÁRIA E CONCORRÊNCIA DE TRAJETÓRIAS}

A dinâmica fundiária se verifica no contexto de concorrência de trajetórias tecnológicas, isto é, como derivação das decisões de mudança e inovação tomadas em ambiente de incerteza, que incorporam as possibilidades e limites do meio institucional e natural onde ocorrem (NELSON e WINTER, 1982; DOSI, 2006; COSTA, 2014). Na perspectiva indicada por Arthur (1994b, p.13-32), tais decisões são path-efficient. Isto é, uma trajetória tecnológica será reiteradamente escolhida em detrimento de outras se os rendimentos a ela associados se mostrarem superiores aos que se associam às suas concorrentes.

Os rendimentos associados às trajetórias têm dois componentes em duas dimensões. Um componente representado pelos "filtros econômicos" seletores das adoções, na concepção de Dosi (2006), resultado dos ganhos derivados da aplicação da tecnologia stricto senso, implicando em variações na produtividade física, e das oportunidades de mercado, expressas em preços. Outro componente são rendimentos associados ao contexto institucional - de externalidades positivas derivadas do grau de adesão que desfruta uma trajetória em dado contexto (ARTHUR, 1994), onde se incluem ganhos em termos de custo de transação (COASE, 1937; NORTH, 1990; WILLIAMSON, 1996) e outros rendimentos derivados da ação coordenada dos agentes, a que se refere Ostrom (1990). Tais componentes se expressam em dimensões meso e microeconômicas, respectivamente, nos fluxos agregados de renda resultantes da produção e suas articulações backwards e forwards e na remuneração dos agentes que controlam a produção.

$\mathrm{Na}$ análise que segue, discutiremos os ganhos que justificam permanência ou mudança de trajetória (o deslocamento dos recursos de uma para outra), em dimensão meso, apoiados na proxy da Produtividade Monetária do Trabalho (PMTb), a qual têm dois fundamentos: a Produtividade Monetária da Terra (PMTr) e a Relação Terra-Trabalho (RTrTb), tal que PMTb = PMTr $x$ RelTrTb (ver na Tabela 1, notas 2, 3 e 4). Em perspectiva micro, para as empresas camponesas, cujo processo decisório se orienta por eficência reprodutiva (COSTA, 1995; COSTA, 2007a, 2007b; COSTA, 2012b) utilizaremos a proxy de Renda Líquida por Trabalhador Equivalente (RLTb: ver nota 5 da Tabela 1); para as empresas patronais utilizaremos uma proxy da Taxa de Lucro (TxL: ver nota 6 da Tabela 1) representada pela Renda Líquida (RL: VBP menos Custos de Produção) dividida pelos Custos de Produção (CP). Não temos como estabelecer nessas variáveis o peso específico do componente institucional. Como indicação de maior ou menor participação institucional recorreremos ao Índice de Densidade Institucional a Partir do Crédito (IDIC: ver nota 7 da Tabela 1): resultado da divisão da participação relativa no crédito pela participação relativa no VBP, e dados relativos à mobilização de terras pelo mercado de terras e pelos mecanismos de reforma agrária e distribuição de terras.

O IDIC, apesar de calculado a partir do crédito, dá indicações sobre um espectro mais amplo de questões. É que o crédito rural é fundamentalmente crédito de fomento 
e, como tal, mecanismo de política. De modo que, em torno dele movimentam-se outras políticas - suas instituições e organizações mediadoras - sendo as mais expressivas as que definem o acesso à terra, as de pesquisa tecnológica e as de assistência técnica. Ademais, o crédito reflete o estado geral do ambiente institucional nas áreas rurais. Pois, onde há políticas de ordenamento territorial, há crédito; onde as relações de propriedade da terra são dúbias, não há crédito; ou, se existe apesar disso, há algum tipo de governança que o garante.

As ações formais de reforma agrária, por seu turno, estabelecendo segurança fundiária, habilitam os beneficiários ao acesso de outros mecanismos de política e ação institucional, como o próprio crédito.

\subsubsection{ACUMULAÇÃO FUNDIÁRIA E ARRANJO INSTITUCIONAL}

A T4, em 1995, era, com larga vantagem, a mais importante trajetória patronal de produção rural. Ao mesmo tempo, apresentava, com 60\% das terras apropriadas, o maior peso, entre as trajetórias, na estrutura fundiária da Região Norte. Não obstante, naquele ano do Censo apresentava a segunda maior taxa de lucros entre as trajetórias patronais (80\%), perdendo para a Trajetória Patronal T5 (103\%), composta por 4.444 estabelecimentos que reuniam o conjunto de sistemas patronais que convergiam para plantações especializadas de culturas permanentes em forma de plantation. Marcada por uso intensivo do solo e homogeneização da paisagem, trata-se de trajetória com baixa formação de dejetos e impacto poluidor.

Consideradas as taxas de lucros, poder-se-ia esperar uma preferência equilibrada dos agentes entre as duas trajetórias, a T4 e a T5, ou, até mesmo, uma adoção maior da última em comparação com a primeira, correspondendo a diferenças de lucratividade. Dadas as profundas diferenças entre as duas trajetórias no que diz respeito à intensidade do uso da terra (a PMTr da T5 é aproximadamente 1/3 maior e a RelTrTb 1/3 menor que a T4) e à intensidade de carbono (T5 0,31; T4 1,36 t/R \$), a realização de tal possibilidade teria colocado condições bem distintas para o desenvolvimento rural da região. Não obstante, naquele ano do Censo a T4 participava com $28 \%$ do setor rural enquanto a $\mathrm{T} 5$ com meros $4 \%$.

O viés, pois, que, na Amazônia, operou em favor de uma estruturação com as características da T4 tem explicação mais institucional que econômica. Um primeiro elemento institucional a ser considerado diz respeito à política de crédito de fomento, com juros subsidiados, que favoreceu a T4, uma vez que, em 1995, a proporção dos recursos de crédito a ela destinada era $60 \%$ maior que sua importância econômica (IDIC de 1,6: para cada 1\% de participação no VBP, 1,6\% de participação na política 
de crédito). Ocorre que a T4 esteve em segundo lugar entre os favorecidos pelo arranjo institucional formal de alocação de recursos de capital, via crédito, atrás precisamente da Patronal T5, para qual se concederam 3,5 pontos percentuais de participação na política de crédito para cada ponto percentual de participação no VBP (ver Tabela 1).

Não terá sido o crédito sozinho, portanto: o que garantiu o peso atingido pela T4 foi o arranjo institucional informal que funciona na Amazônia como mercado de terras novas. O crédito formal atuou como reforço de capitalização e capacitação tecnológica.

Uma característica da T4 é sua grande exigência em terras: em 1995, metade (51\%) do rebanho bovino pertencia a estabelecimentos com capacidade de suporte médio em torno de 0,6 cabeças/ha e metade a estabelecimentos em torno de 0,9 cabeças (COSTA, 2009, p.134). Ademais, demonstrou-se que as tecnologias de intensificação eram inviáveis para estabelecimentos de menor escala, só se tornando modestamente efetivas em escala média de 5.000 cabeças e, ainda, que a lucratividade dos estabelecimentos crescia com o tamanho do rebanho, mesmo mantidas as técnicas extensivas em terras (COSTA, 2009, p.140). Em tal contexto, melhorias técnicas path-efficient atuam mais sobre os rebanhos que sobre a capacidade de suporte "e o crédito institucionalizado que internaliza esses avanços (...) atua fortemente no incremento da escala de produção. Dela emana, correspondentemente, uma enorme tensão de incorporação de novas terras" (COSTA, 2009, p.141).

A incorporação de terras novas ao acervo fundiário dos estabelecimentos se fez no contexto de um mercado de terras, entendido como um amplo mecanismo institucional (POLANY, 1992) composto de dois processos combinados, de produção e venda de terras (COSTA, 2011; COSTA, 2012). O processo de produção de terras transforma, dominantemente por mecanismos informais e ilegais (BRASIL, 2002, p.37-38), acionados por uma ampla rede de agentes (GAYOSO DA COSTA, 2012, p.161-64), em primeiro movimento, "Florestas Originárias" (ativo específico, não mercadoria, bem público) em “Terras com Mata” (ativo genérico, mercadoria, bem privado). Na condição de ativo privado e genérico, “Terras com Mata” tornam-se, em um segundo momento, a matéria-prima comum na produção de mercadorias-terras com destinação específica: “Terras de Pastagem" ou "Terras para Lavoura”.

Com tal arranjo institucional, a T4 acumulou um acervo fundiário que, em 1995, era de 33 milhões de hectares $-60 \%$ do total acumulado por todos os estabelecimentos na Região Norte; como subproduto, uma extensão de áreas degradadas de 2,2 milhões de hectares, que equivalia a $64 \%$ do verificado para todo o setor rural, e uma produção cuja densidade de $\mathrm{CO}_{2}$, de $1,36 \mathrm{t} / \mathrm{R} \$$, era mais que o dobro da média regional (0,6 t/R $\left.\$\right)$. A seu tempo, no período intercensitário, o mercado de terras supriu com abundância as necessidades da T4 de Terras com Mata, a preços continuamente baixos: se estima que 11,2 milhões de hectares de terras novas foram incorporados pela T4 nesse meio tempo (conf. COSTA, 2012, p.261-263). 


\subsubsection{DESLOCAMENTOS FUNDIÁRIOS E MUTAÇÃO DA T4}

No período entre os censos, a T4 sofreu expressivas mudanças, iniciando pela mais fundamental de todas: o deslocamento de parcela substancial de seus recursos fundiários para diferentes trajetórias. Tais transferências se fizeram, ou porque os estabelecimentos sofreram uma conversão para outra trajetória, por decisão de seus operadores, mudaram técnicas, processos e produtos, ou porque, como "espólios", os recursos de estabelecimentos fracassados em uma trajetória, são absorvidos por estabelecimentos já situados em outras trajetórias. Em um caso, como no outro, podemos falar de deslocamento de recursos entre trajetórias, em um processo em que a recebedora se constitui ganhadora de um processo de concorrência. Ao final, por qualquer dos caminhos, ter-se-á um processo de mutação e evolução que se reconhecerá no seu resultado: as trajetórias que prevalecem. Há, todavia, outras situações, em que transferências de acervo ocorrem ou porque estes existem, mediante alguma estratégia, como reservas, ou porque se trata de recursos tornados excedentes, mediante precisamente um processo de mudanças.

Os deslocamentos para as trajetórias patronais T7, T6 e T5 se fizeram como transmutação da T4 e serão tratados neste segmento. Os deslocamentos para as trajetórias camponesas serão tratados no próximo segmento como deslocamento de recursos excedentes.

Para a T7, trajetória que emerge precisamente no período entre os Censos e se caracteriza pela produção intensiva de grãos, particularmente soja e milho, em bases mecânico-químicas, deslocaram-se 3,8 milhões de hectares que em 1995 faziam parte do acervo de 33,3 milhões de hectares da T4 (ver Gráfico 1). Outros 3,8 milhões de hectares deslocaram-se da T4 para a Trajetória Patronal T6, a qual reunia o conjunto de sistemas patronais de silvicultura operados em 1995 por apenas três grandes estabelecimentos. Marcada por uso extensivo do solo, a embrionária T6 se caracterizava por homogeneização da paisagem (alto impacto na biodiversidade), explicando $2 \%$ do VBP e 0,2\% do emprego. Em 2006 a T6 apresentava um acervo de 4,2 milhões de hectares, dos quais 0,4 milhões eram remanescentes de 1995. A esses se juntaram os já mencionados 3,8 milhões de hectares provindos da T4.

\section{Gráfico 1 - Dinâmica do acervo fundiário da T4 no período intercensitário (em milhões de hectares)}

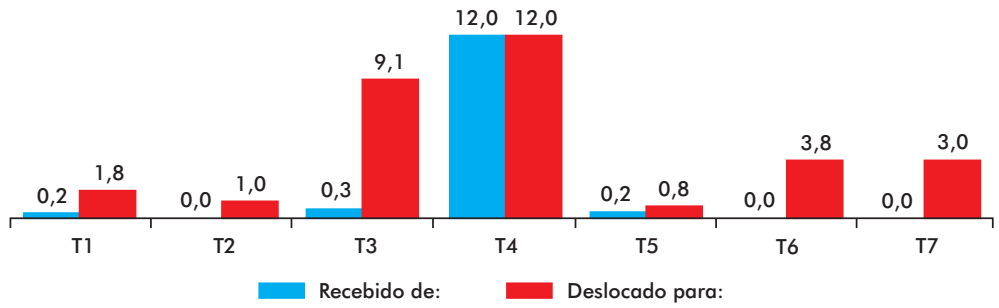

Fonte: Elaboração própria com base em tabulações especiais dos autores e dados do Censo Agropecuário 1995 e 2006. 
A Trajetória Patronal T5 (plantation empresarial), antes apresentada, encerra, com a absorção de 0,8 milhões de hectares, o rol de trajetórias tecnológicas empresariais supridas pela T4 com recursos fundiários.

Os seletores econômicos tornam compreensivas as mudanças na T7 e na T6, trajetórias que receberam as maiores parcelas de recursos fundiários da T4. A T7 combinou PMTb e PMTr superiores, respectivamente, 154\% e 62\%, com uma TxL que era quase o dobro (15\%) da T4. A T6, por sua vez, compensou PMTbePMTr inferiores (respectivamente $51 \%$ e $79 \%$ ) à T4, com uma TxL explosiva, de $86 \%$ (para estes e os resultados que seguem ver Gráfico 2). Ambas as trajetórias cresceram no período, chegando a recém estabelecida T7 a representar 6\% e a T6 3\% (um ponto percentual acima do que fora em 1995) do VBP do setor rural da Região Norte em 2006.

\section{Gráfico 2 - Evolução no período intercensitário da produtividade monetária dos fatores, da taxa de lucro e da densidade institucional das trajetórias patronais que receberam recursos da T4}
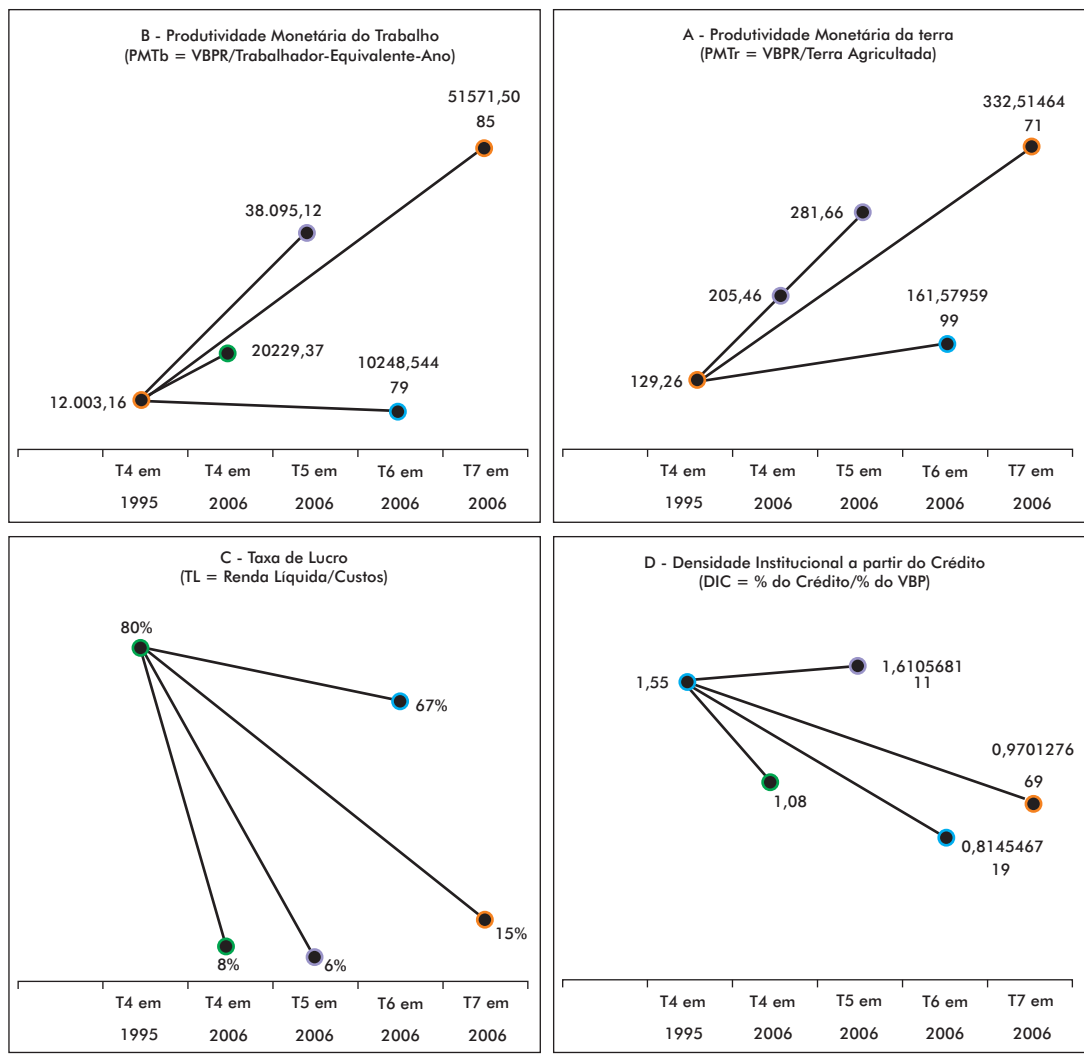

Fonte: Elaboração própria com dados da Tabela 1. 
Para o caso dessas trajetórias não se verifica uma influência institucional perceptível no IDIC, que se mostra equivalente para a T4 e a T7 $(1,1$ e 1,0$)$, com diferença apenas ligeiramente maior quando se trata da T6 $(0,8)$. Na relação com a T5, entretanto, terá sido decisiva a mediação institucional do crédito: com TxL, PMTb e PMTr inferiores à T4, a IDIC de 1,6 poderá ter sido um indutor dos deslocamentos fundiários de 0,6 milhões de hectares que para a T5 se constataram. Mesmo assim, de dimensões já modestas em 1995, quando explicava 6\% do VBPR, 2\% do emprego, $2 \%$ da área degradada e 3\% do balanço líquido de carbono (ver Tabela 1), a T5 se apresenta em dimensões ainda menores em 2006 (989 estabelecimentos, 2\% do VBPR e 1\% do emprego).

Falta observar, para finalizar este tópico, que a T4 sofreu mudanças, ela mesmo, chegando a 2006 com PMTb 69\% e PMTr 58\% superiores ao que foram em 1995. A TxL, entretanto, chegou a não mais que $1 / 10$ da passada e a IDIC reduzida em 1/3. Assim, a T4 passa a representar $14 \%$ do VBP (1/2 de sua expressão passada), $7 \%$ do emprego e $23 \%$ do acervo fundiário.

\subsubsection{DESLOCAMENTOS FUNDIÁRIOS DA T4 PARA TRAJETÓRIAS CAMPONESAS}

No tópico anterior, vimos a transferência de recursos fundiários como parte de processos de transmutação evolucionária de parte da T4 em, pela ordem de importância, T7, T6 e T5. Outras situações de transferências de acervo fundiário ocorreram como venda de recursos excedentes: reservas de "Terras com Mata” ou terras tornadas excessivas no processo de mudança de trajetória que se assistiu.

Nessas condições, a T4 cedeu recursos expressivos para trajetórias camponesas: 9,1 milhões de hectares para a T3, 1,8 milhões para a T1 e 1,0 milhão para a T2 (ver Gráfico 1). Ao todo, 11,9 milhões de hectares.

A Trajetória Camponesa T3 reunia em 1995 o conjunto de sistemas de produção camponeses que, no interior de 109.405 estabelecimentos, convergiam para sistemas com dominância de pecuária de corte, apesar de apresentarem grau elevado de diversificação. A trajetória explicava então 19\% do VBPR, 28\% do emprego, 14\% da área degradada e $12,5 \%$ do balanço líquido de carbono (Tabela 1). No período intercensitário, ela sofreu uma notável ampliação, crescendo em importância na pecuária de corte, com recursos deslocados da T4, como já mencionado, e absorvendo a pecuária leiteira da T1, da qual incorporou 4,1 milhões de hectares. Voltaremos a esta última questão em 3.3.

A Trajetória Camponesa T1, que absorveu 1,8 milhões de hectares da T4, reunia em 1995 o conjunto de 171.292 estabelecimentos camponeses cujos sistemas de produção convergiam para a dominância de uma agropecuária relativamente intensiva, baseada em culturas permanentes e produção de leite, atividades das quais produzia 
respectivamente, 49\% e 39\% do valor da produção na Região Norte. A T1 representava em 1995 a mais importante trajetória camponesa, respondendo por $27 \%$ do VBPR e $38 \%$ do emprego. Retornaremos à T3 e a T1 em 3.3, uma vez que elas protagonizam eventos associados a arranjos institucionais particulares.

A Trajetória Camponesa T2, que recebeu a menor, porém expressiva parcela de 1 milhão de hectares da T4, reúne os estabelecimentos camponeses que convergem para sistemas agroflorestais. Na subseção 3.2 nos dedicaremos a esta importante estruturação.

No momento, importa verificar os fundamentos das mudanças. Em perspectiva meso, a PMTb e a PMTr cresceram acentuadamente em todas as trajetórias. Em perspectiva micro, como motivador e resultado do processo de absorção de recursos, se deve assinalar o incremento observado na RLTb da T1, de 213\%, da T2, de 190\%, e da T3, de 27\% em relação à RLTb de 1995. Esclareçamos melhor esse ponto. Em 1995 a T3 tinha a maior RLTb entre as trajetórias camponesas: R \$ 3.096,56, 11\% superior à da T2 e 11\% superior a da T1. A sua forte expansão tem aí um ponto inicial de explicação: resultado da atração do maior payoff, o qual, por seu turno, cresceu com as adesões, como prevê o modelo de Arthur (1994). Aliás, a hipótese de Arthur aduz que parte do crescimento do payoff de uma trajetória como resultado de adesões, deriva da maior adequação, correlata a expansão, que sofre o ambiente institucional em seu favor.

Com efeito, a participação institucional indicada pelo IDIC cresceu acentuadamente no período apenas na T3, de 0,66 para 1,6. Para a T1, reduziu de 0,74 , a maior em 1995 entre os camponeses,para 0,64 e para a T2 se manteve basicamente a mesma: 0,39 e 0,42 , a menor IDIC em um ano como no outro.

Uma decisiva mediação institucional se fez pela política de reforma agrária e redistribuição de terras. Entre 1995 e 2006, em diversas modalidades de assentamentos, o INCRA redistribuiu ou garantiu posses de terras para camponeses voltados para a agropecuária, da T3 e da T1, em um montante de 15,5 milhões hectares, além de ter garantido o acesso a recursos fundiários em assentamento extrativistas da ordem de 3,8 milhões de hectares. Tais valores abrigam com folga as transferências da T4 de 11 milhões para a T3 e a T1 e de um milhão para a T2.

A política de redistribuição de terras teve a T4 como objeto, garantindo recursos fundiários à T3. A política de crédito, por sua vez, garantiu a esta última aquisição dos demais ativos da T4 em transmutação, principalmente gado. Seria tema para pesquisa por vir, com base na demonstração dos valores monetários envolvidos nessas transferências, estabelecer o quanto a política de reforma agrária capitalizou a T4, por uma parte; por outra, o quanto essa política negou ou corroborou o mercado de terras: se o fato da T4 ter sido objeto da reforma agrária se deveu à impropriedade de seus fundamentos fundiários, uma ilegalidade revelada e corrigida (nesse caso, os deslocamentos 
fundiários não correspondem a retornos financeiros); ou se isso resultou de um poder de definição das regras institucionais por parte do arranjo institucional informal vigente, a tal ponto, que se legitimaram, por que se realizaram mais uma vez como mercadoria, os produtos do mercado de terra (nesse caso, os deslocamentos implicaram em retornos financeiros).

\section{Gráfico 3 - Transferência de terras para as trajetórias camponesas por via da política de reforma agrária entre 1995 e 2006}

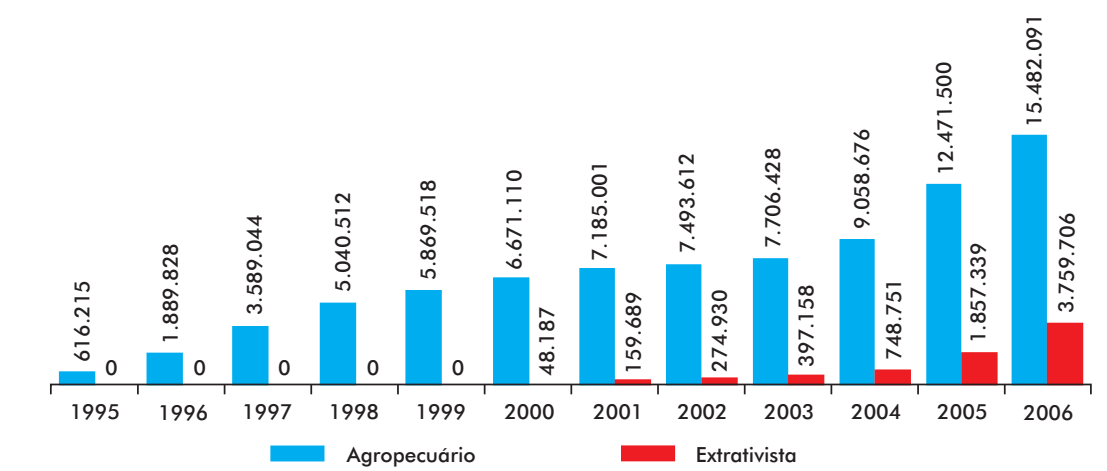

Fonte: Elaboração própria com dados do Instituto Nacional de Colonização e Reforma Agrária (INCRA), Diretoria de Gestão Estratégica, Coordenação Geral de Monitoramento e Avalização da Gestão (DEA).

\subsubsection{DINÂMICA DE TRAJETÓRIA E SUSTENTABILIDADE AMBIENTAL}

O desmatamento, na extensão que compromete a sustentabilidade ambiental, tem sido fenômeno inerente ao desenvolvimento da $\mathrm{T} 4 \mathrm{em}$ sua forma original, resultado de suas tecnologias extensivas em terra. Por outro lado, o protagonismo da T4 nas mudanças ocorridas no período intercensitário manteve, ou, mesmo, fortaleceu a dominância de tecnologias extensivas em terras. Com efeito, o processo de transmutação da T4 em T7, o mais importante trajeto de mudança verificado, resulta numa $\mathrm{RTrTb}$ (relação terra/trabalhador) de 155,1 ha/TbEq em 2006, maior, ainda, que a já muito elevada, de 92,86 ha/TrEq, prevalecente na T4 em 1995. Aliás, esta relação aumentou na T4 remanescente para 98,85 ha/TrEq em 2006. Por sua vez, a prevalência da T3 sobre outras trajetórias camponesas, pela importância da pecuária em seus sistemas, se faz acompanhar de forte crescimento na RTbTr que, já comparativamente alta em 1995 (9,44 ha/TbEq, para 6,35 da T1 e meros 2,02 da T2), praticamente triplica, atingindo, em 2006, 28,03 ha/TbEq. Estes são indicadores de tensões que podem manter altos, ou mais elevados do que seria possível, os níveis de risco ambiental associado a desmatamento. 


\subsubsection{DINÂMICA DE TRAJETÓRIA, ARRANJO INSTITUCIONAL E TERRITÓRIO}

$\mathrm{O}$ arranjo institucional descrito tem territorialidade precisa: aquela desenhada pela evolução da T4 até seu auge em 1995. Como se verifica no Gráfico 4, que apresenta a distribuição do VBP da T4 por mesorregiões em 1995, a Ocidental do Tocantins (que engloba as microrregiões do Bico do Papagaio, Araguaína, Miracema do Tocantins e Rio Formoso), conjugada com o Sudeste Paraense (que engloba as microrregiões de Marabá, Paragominas, São Félix do Xingu, Parauapebas, Conceição do Araguaia e Redenção) compõem o núcleo territorial principal de vigência do arranjo. Deve-se notar que essa é a área da tensa evolução da fronteira agrícola dos anos sessenta aos noventa, demarcando a área que se tornou conhecida como "arco do desmatamento", ou "arco do fogo" (BECKER, COSTA e COSTA, 2010). A mudança na estrutura da economia rural nessa região, que se processou no período entre os censos se demonstra no Gráfico 5: na Ocidental do Tocantins a T4 saiu de um peso de nada menos que $77 \%$ na economia rural em 1995, para 39\% em 2006, emergindo as patronais T5 e T7, que no conjunto passaram a representar próximo de $10 \%$ da economia. A T3 cresceu em importância de 20 para $46 \%$ da economia rural. No Sudeste Paraense a T4 representava em 1995 a metade da economia rural, chegando em 2006 com 39\%. Em compensação, emerge a T7 com 18\% e a T6 com $2 \%$. A camponesa T3 praticamente duplica em importância, saindo de $17 \%$ para $32 \%$.

Gráfico 4 - Distribuição do VBP da T4 por mesorregião em 1995 (\% do total)

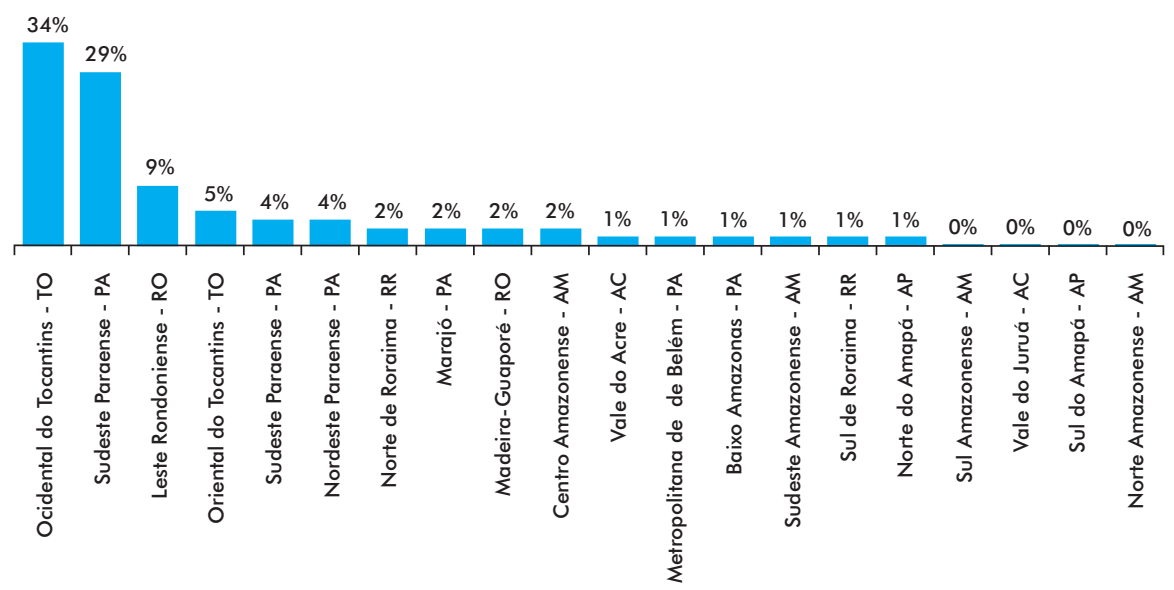




\section{Gráfico 5 - Dinâmica de concorrência de trajetória} nos territórios da T4 entre 1995 e 2006

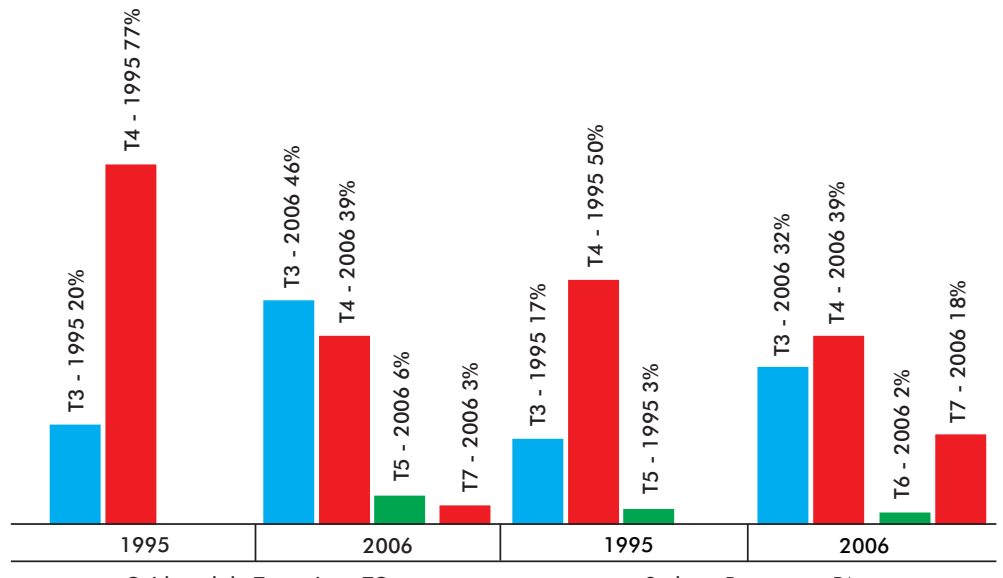

Ocidental do Tocantins - TO

Sudeste Paraense - PA

Fonte: Elaboração própria com base em tabulações especificais dos autores e dados do IBGE, Censo Agropecuário de 1995

\subsection{DINÂMICA ECONÔMICA DA T2 E GESTÃO DE RECURSOS COMUNS: DESENVOLVIMENTO VERDE E INCLUSIVO}

A Trajetória Camponesa T2 reunia em 1995 o conjunto de 130.593 estabelecimentos camponeses que convergiam para sistemas agroflorestais. Respondia, no ano mencionado, por $18 \%$ do VBPR total da região e $26 \%$ do emprego rural. Em contraste que merece ser sublinhado, no mesmo ano, sua participação na formação de áreas degradadas não passava de meros 3,5\% do total e, no balanço líquido de carbono não passava de 2,6\% das emissões líquidas totais.

No Censo de 2006, a T2 se apresenta acrescida, contando com 156.728 estabelecimentos que conjuntamente produziam 27\% do VBPR ocupando 33\% dos trabalhadores na economia rural da região (ver Tabela 1). Observe-se que esta é uma trajetória expressão de um paradigma agroextrativista - no qual os processos produtivos pressupõem, em algum nível, a preservação da natureza originária, constituindo, assim, forma de gestão e valorização econômica da floresta em pé. Com efeito, em 1995, 60\%, e, em 2006, 90\% do VBPR de produtos florestais não madeireiros na região provieram da T2 (ver Tabela 1). Além da presença fundamental de atividades que manejam a floresta originária, a T2 abriga uma importante produção de farinha de mandioca e atividades de recomposição de cobertura vegetal estável, o que se demonstra pela importância de culturas permanentes e de silvicultura, as quais, no caso das primeiras, saíram de $16 \%$ para $42 \%$ e, da segunda, de $1 \%$ para $37 \%$ do valor da produção regional entre os anos do Censo (ver Tabela 1). 


\subsubsection{NOVAS BASES ECONÔMICAS E RELAÇÕES DE MERCADO DA T2}

No período entre os censos se estabeleceram novas mediações institucionais nas relações da T2 com o mercado, que substituem as antigas relações com o capital mercantil, de elevada assimetria, por contratos com a presença crescente do capital industrial, mais exigentes, por uma parte, mais regulares e, a depender de circunstâncias, menos assimétricos, por outra parte (para o que prevalecia por ocasião do Censo de 2006, ver COSTA et al., 2006). Uma indicação de mudanças nas relações entre os setores urbanos e a T2 é o fato de que a Renda Líquida por Trabalhador (RLTb) cresceu 189\% no período aqui tratado.

$\mathrm{O}$ crescimento da T2 e as mudanças assinaladas se estabeleceram sob o peso de múltiplas determinações, destacando-se: a) ampliação e a crescente sofisticação dos mercados de consumo para os produtos naturais em geral, os produtos florestais em particular e, especialmente, para aqueles oriundos da chamada "biodiversidade amazônica"; b) incorporação de novas tecnologias em várias das cadeias produtivas dessas atividades, processo que pode ser basicamente relacionado à maior conectividade entre as atividades de C\&T e de P\&D da Região e de fora dela com esses sistemas; c) novas exigências dos mercados de consumo expressas em mecanismos diversos de autorregulação que têm sido adotados para a certificação de qualidade em geral e es-

pecificamente ambiental; e d) modalidades mais avançadas de produção e de integração, e a nova logística introduzida pelas grandes empresas agroindustriais (BECKER, COSTA e COSTA, 2009, p.152).

\subsubsection{BASE FUNDIÁRIA DA T2 E NOVAS MEDIAÇÕES INSTITUCIONAIS}

O acervo fundiário da T2 cresceu significativamente, recebendo 2,3 milhões da T1 e 1,0 milhão da T4, já acima discutida (ver Gráfico 1). Recentemente, a política de reforma agrária atingiu a T2: entre 2001 e 2006, 3,7 milhões de hectares haviam sido garantidos em diferentes formatos para populações associadas à trajetória (ver Gráfico 3, assentamentos extrativistas; sobre formas e processos ver MAIA, 2011; THOMAS, 2014).

\subsubsection{DINÂMICA ECONÔMICA DA T2 E ARRANJOS INSTITUCIONAIS DE GESTÃO DE RECURSOS COMUNS}

O crescimento da T2 foi acompanhado, como já se mencionou, de uma elevação muito acentuada da RLTb, em 190\%, de R\$2.578,05 em 1995, para 7.468,49 em 2006. Essa é 
uma indicação de que no âmbito da T2 se verificaram, no período entre os censos, condições de redução da pobreza. Acresce que a PMTb, por sua vez, variou correspondentemente, em 205\%, de R\$2.823,96 em 1995 para R\$ 8.604,48 em 2006, e a PMTr atingiu R\$959,15.

Cabe observar, neste ponto, que este valor da PMTr da T2 é o maior entre todas as trajetórias. Como se explica, porém, que precisamente uma trajetória que tem o manejo da floresta originária entre seus fundamentos produtivos, pode ter a mais alta produtividade da terra? A resposta para isso é a seguinte: os estabelecimentos da T2 compõem suas rendas com recursos obtidos nos seus lotes privados (aliás, os menores, entre todas as trajetórias, com médias de 22 e 44 ha por estabelecimento, respectivamente, em 1995 e 2006, ver Tabela 1) e com recursos obtidos em áreas de acesso comum. Várias são as formas dos arranjos que para tanto se fazem, presentes em todos os territórios da T2 (NOGUEIRA, 2015; DA COSTA, 2014; MARIN, 2014; GUMIER, 2012; DINIZ, 2011; BRONDOZIO, 2009 e 2006; MOURA, 2007).

\subsubsection{O TERRITÓRIO DA T2 E A GESTÃO DE RECURSOS COMUNS}

A territorialidade da T2, com seus arranjos institucionais, tem configuração antiga, eis que suas estruturas mais importantes foram formadas ainda no século XVIII (COSTA, 2011; COSTA, 2012). Em 1995, as mesorregiões contíguas Nordeste Paraense (principalmente as MRH Cametá e Tomé-Açu), Marajó e Metropolitana de Belém conformavam seu principal núcleo territorial, produzindo 45\% do total do VBP da trajetória (Gráfico 6). Destacam-se, ademais, as mesorregiões Norte, Sudeste e Sul Amazonense, em conjunto, $14 \%$. No todo, se mostra a presença da trajetória nas regiões da Amazônia, nas quais uma economia baseada nos recursos do bioma e seus ecossistemas tem presença histórica.

A importância da T2 nessas mesorregiões, medida pela participação do seu VBP no VBP rural total de mesorregião, cresceu no Nordeste Paraense de $58 \%$ para $63 \%$, na Marajó de 51 para 95\% e na Metropolitana de Belém de 36\% para 45\%; ainda no Pará, no Baixo Amazonas atingiu 34\%. No Amazonas, cresceu em todas as mesorregiões com exceção da Norte Amazonense, atingindo participação elevada de 57\% no Sudeste e $43 \%$ no Centro Amazonense. 
Gráfico 6 - Distribuiç̧ão do VBP da T2 por mesorregião em 1995 (\% do total)

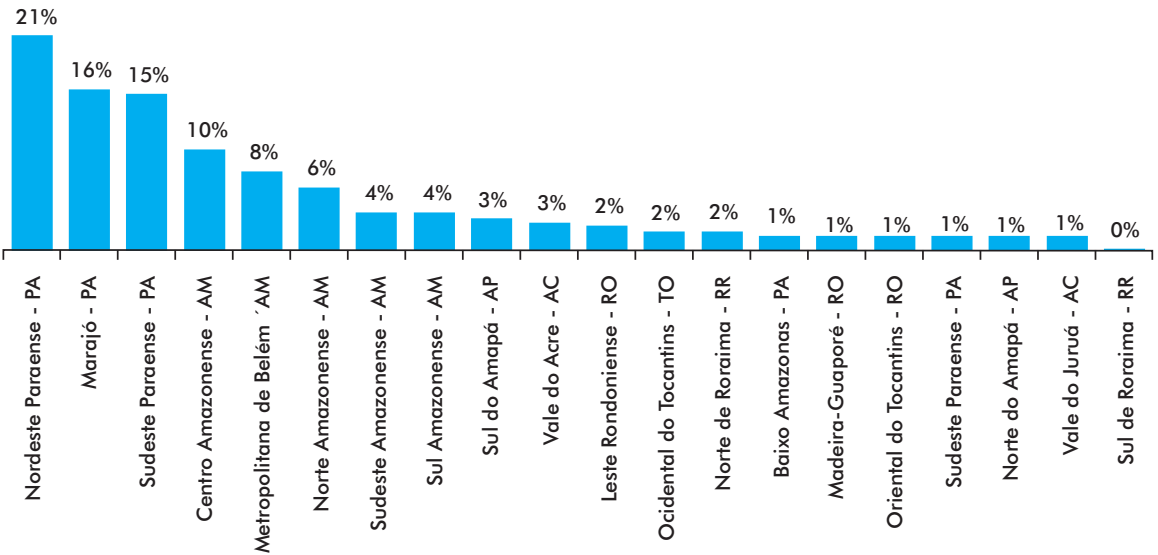

Fonte: Elaboração própria com base em tabulações especificais dos autores e dados do IBGE, Censo Agropecuário de 1995.

\section{Gráfico 7 - Evolução da importância da T2 nas mesorregiões entre 1995 e 2006 (\% da T2 no total do VBP)}

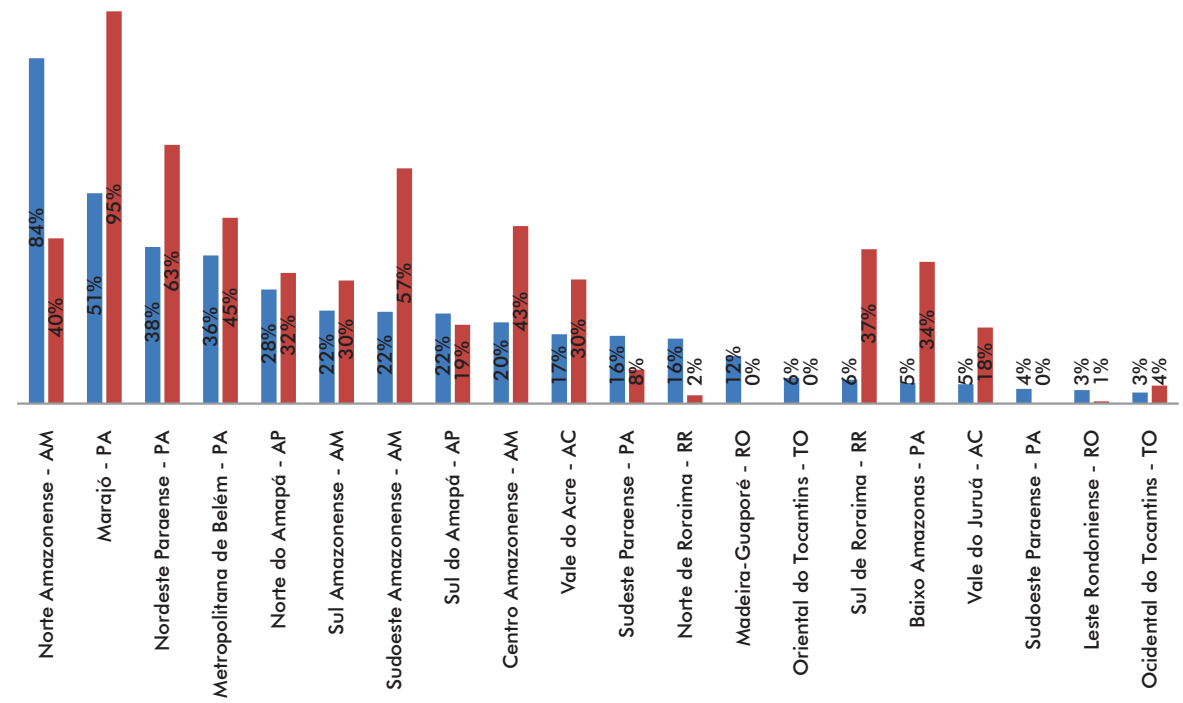

Fonte: Elaboração própria com base em tabulações especificais dos autores e dados do IBGE, Censo Agropecuário de 1995.

O avanço significativo da T2 em termos de sua participação relativa no VBP de várias mesorregiões, de sua taxa de crescimento absoluto e da melhoria nos indicadores de produtividade e rentabilidade - derivados em grande medida da sustentação institucional do ambiente de governança histórico tradicional agroextrativista baseado na lógica dos commons - parece ter na melhoria do ambiente de mercado nacional e 
internacional (que, na última década, tem favorecido a ampliação dos mercados para produtos agroextrativistas da Amazônia) o fundamento mais imediato a impulsionar o crescimento de sua atividade produtiva, mesmo sem apoio institucional formal do Estado: a esse respeito, considere-se o nível da densidade institucional da T2 informada a partir do crédito, o mais baixo IDIC entre todas as trajetórias, tanto em 1995, quanto em 2006: respectivamente, de 0,39 e 0,42.

A experiência relativa ao ambiente institucional da T2 (com o peso de seus fundamentos históricos de governança informal com base em princípios de gestão de recursos comuns) demonstra, assim, a necessidade de se compreender a existência de diferentes arranjos institucionais que se formam historicamente compondo territórios diferenciados, com necessidades distintas.

Neste caso, a preservação do ambiente de governança baseado na lógica da gestão de recursos comuns, por parte dos produtores agroextrativistas da T2, parece ser requisito de política de desenvolvimento que mais se alinha aos anseios e ideais do desenvolvimento sustentável na Amazônia. Ademais, fundamentos de produtividade física positivos, aliados a indicadores de preservação ambiental e melhorias no combate à pobreza, parecem apoiar a percepção de que, se aliado a uma adequada política de crédito e melhorias no sistema logístico e organização produtiva, para além do fortalecimento de sua base de conhecimento sobre o manejo dos recursos naturais, a evolução e sustentação inovadora do ambiente institucional da T2 pode representar um caminho alternativo importante na busca pela consolidação de uma nova base produtiva, aos moldes da proposta da noção de economia verde.

\section{CONSIDERAÇÕES FINAIS}

O que se apresentou ressalta a importância da consideração da diversidade de agentes e estruturas na compreensão dos arranjos institucionais que fundamentam as governanças territoriais. O setor rural da Amazônia, representada pela Região Norte, no período entre os censos agropecuários de 1995 e 2006, se define por uma heterogeneidade estrutural profunda: estruturas em movimento por decisão de distintas racionalidades, camponesas ou patronais, mobilizando recursos naturais próprios de uma região, conformam diferentes trajetórias tecnológicas, as quais, em dinâmica de concorrência ou cooperação, com a mediação de instituições, definem as configurações territoriais.

Distinguindo padrões de desenvolvimento mediante concorrência de trajetórias, revelam-se os arranjos institucionais. Duas grandes configurações foram postas em relevo: 
A primeira configuração analisada evolui sob a influência do protagonismo estrutural da Trajetória Patronal T4 (pecuária de corte), por uma parte, em processo de transmutação principalmente para a Trajetória Patronal T7 (produção de grãos), mas também para a T6 (silvicultura) e a T5 (culturas permanentes); por outra, transferindo recursos para a Trajetória Camponesa T3 (ênfase em pecuária).

A arena territorial dos processos são as regiões interiores de terra firme da Amazônia, abertas à fronteira agrícola pelas estradas construídas nos anos sessenta e setenta e pelos incentivos, fiscais, creditícios e fundiários, que perduraram até meados dos anos oitenta. A arena institucional é dominada pelo arranjo institucional informal do mercado de terras, com seus mecanismos, alguns ilegais, de produção e venda de terras. Esse arranjo, fornecendo terras baratas, garantiu a economicidade da T4, baseada em tecnologia de uso extraordinariamente extensivo da terra, e sua notável expansão, seu controle territorial expresso, em 1995, na posse de $60 \%$ de todo o acervo fundiário dos estabelecimentos da região.

Duas mediações institucionais formais de grande relevância no desenvolvimento rural da região se definiram, em suas operações e resultados, em associação a esse acervo acumulado com a mediação do mercado de terras até 1995. A política de crédito, que, completamente reconfigurada desde fins dos anos noventa, com o Fundo Constitucional do Norte (FNO), passa a chegar, em proporções sem precedentes, aos estabelecimentos camponeses, e a política de reforma agrária e redistribuição de terras, também atuante com força no período entre os censos: ambas interagiram produzindo a transferência de recursos da T4 para a T3. A rigor, essas políticas formais passaram a compor, com o mercado de terras, a governança territorial multiescalar que permeia as relações entre as trajetórias.

A outra configuração das relações entre trajetórias tecnológicas e instituições destacada tem a Trajetória Camponesa T2 (sistemas agroflorestais) como referência. Seu território se constitui fundamentalmente das regiões de colonização mais antiga da Amazônia e nele prevalecem governanças informais de acesso a recursos comuns das florestas, rios e lagos. No período entre os censos acresceram-se novas mediações institucionais à realidade da T2. De um lado, a política fundiária de redistribuição de terras atuou também aqui, garantindo a propriedade de áreas em extensão significativa. De outro, novas relações de mercado se estabeleceram na esteira da valorização industrial de produtos da trajetória.

Nestes diferentes contextos, desmatamento e pobreza ganham sentido, assim como as possibilidades de desenvolvimento sustentável e inclusivo.

O desmatamento, na extensão que compromete a sustentabilidade ambiental, tem sido fenômeno inerente ao desenvolvimento da T4 em sua forma original, resultado de suas tecnologias extensivas em terra. As mudanças ocorridas no período intercensitá- 
rio em torno da T4 mantiver a dominância de tecnologias extensivas em terras, tanto na patronal emergente T7, quanto, comparativamente,na camponesa T3.

A pobreza, por seu turno, tem seu contexto estrutural, como o desmatamento, nos fundamentos da produção, em particular das trajetórias camponesas (não se trouxe elementos para a discussão da pobreza que deriva de relações de assalariamento). Sobre isso, a questão se refere à capacidade das técnicas de garantir produtividade crescente e às condições de distribuição dos resultados que ameaçam com a pobreza os gestores dos sistemas produtivos. A T3, no sistema agrário analisado, apresentou produtividade fortemente crescente, com incremento modesto da renda líquida do trabalho: esta, a menor entre todas as trajetórias camponesas, no final do período. Isso aponta para limitações com efeito sobre o poder de compra e capacidade reprodutiva no futuro.

Quanto aos territórios da T2, não é o desmatamento, mas sim, a capacidade de preservação de recursos florestais o fenômeno relevante inerente às suas técnicas e aos arranjos institucionais que têm garantido sua efetividade e eficiência. Importante o reconhecimento de que o crescimento da trajetória se fez acompanhar de produtividade crescente e crescente renda líquida por trabalhador, que quase triplicou entre os censos. Essa é uma indicação de que aqui se percorre uma rota de afastamento da pobreza.

No conjunto, o que se demonstra é uma vitalidade que em nada condiz com a indiferença da institucionalidade formal de fomento do desenvolvimento, aquela informada pela realidade da política de crédito. Tal indiferença em relação à T2 e o contraste precisamente com a atenção dedicada à $\mathrm{T} 3$ no ambiente institucional dominado pela T4 assumem um caráter insólito quando se considera seriamente os atributos de sustentabilidade dos diferentes modelos: a densidade de $\mathrm{CO}_{2}$ da T2 é apenas uma fração das demais trajetórias.

Por fim, o artigo apresenta indicações de que um desenvolvimento com esperança de sustentabilidade e capacidade de redução de pobreza poderá ser almejado. Para tanto, a política deverá respeitar os distintos sistemas agrários (trajetórias tecnológicas rurais em interação) e seus arranjos institucionais. Se nos territórios da T4 coibir o mercado de terras é fundamental, e, portanto, uma ênfase em garantia de property rights de parcelas individuais privadas, no controle do desmatamento e no bloqueia ao acesso dos ativos públicos parecem essenciais e suficientes, na linha defendidos pela NEC, nos territórios da T2, para além disso, vale a ênfase em propriedades coletivas e garantias de direitos de acesso ao bioma, tal como se coloca na discussão dos commons; se políticas de crédito e de desenvolvimento tecnológico são necessárias para reorientar a $\mathrm{T} 3$ nos seus fundamentos produtivos agropecuários, antecipando as crises ecológica e social que suas atuais tecnologias colocam em perspectiva, para a T2 políticas desse tipo parecem ser fundamentais no manejo dos ecossistemas, na logística e na organização da produção. 


\section{REFERÊNCIAS}

ABRAMOVAY, R."Para uma teoria dos estudos territoriais”. In: ORTEGA, A. C.; ALMEIDA FILHO, N. (Org.). Desenvolvimento Territorial: segurança alimentar e Economia Solidária. Campinas: Ed. Alineas, 2007, p. 19-37.

ARTHUR W. B. Competing Technologies, Increasing Returns, and Lock-In by Historical Small Events. In: IncreasingReturns and Path Dependence in the Economy. Michigan: The University of Michigan Press: p. 13-32, 1994.

AYRES, R. "Industrial metabolism”. In AUSUBEL, H.; SLADOVICH, H. E. (Eds.) Technology and environment. Washington, DC: National Academy Press, 1989, p. 23-49.

AYRES, R. Sustainability economics: where do we stand? Ecological Economics, n. 67, p. 281-310, 2008.

BECKER, B., COSTA, F. A., COSTA, W. M. Desafios ao Projeto Amazônia. Brasília: CGEE, 2009.

BRASIL - CONGRESSO NACIONAL. Comissão Parlamentar de Inquérito destinada a investigar a Ocupação de terras públicas na região amazônica. Brasília, DF: Congresso Nacional, 2002.

BRONDIZIO, E. S. "Análise intra-regional de mudanças do uso da terra na Amazônia”. In: MORAN, E. F.; OSTROM, E. (Orgs.). Ecossistemas florestais: interação homem-ambiente. São Paulo: Ed. SEnec/Edusp, 2009, p. 289-326.

BRONDIZIO, E. S. "Intensificação agrícola, identidade econômica e invisibilidade entre pequenos produtores rurais amazônicos: caboclos e colonos numa perspectiva comparada”. In: ADAMS, C. ET AL. (Orgs.). Sociedades Caboclas Amazônicas: modernidade e invisibilidade. São Paulo: Annablume, 2006, p. 195-235.

CHOMITZ, K. Expansão agrícola, redução da pobreza e meio ambiente nas florestas tropicais. Washington, DC: World Bank, 2007.

CHOMITZ, K.; THOMAS, T.S. Geographic patterns of land use and land intensity. (Draft Paper). Washington, DC: World Bank, Development Research Group, 2000.

COASE, R. H. The nature of the firm. Economica, v. 4, n. 16, p. 386-405, 1937.

COSTA, F. A. Políticas de contenção de desmatamento, produção e mercado de terras na Amazônia: Um Ensaio sobre a Economia Local do Sudeste Paraense usando Contas Sociais Alfa (CSa). Revista de Estudos Econômicos, v. 41, p. 621-646, 2011 b.

COSTA, F. A. Mercado de terras e trajetórias tecnológicas na Amazônia. Economia e Sociedade, v. 21, p. $245-273,2012 \mathrm{~d}$.

COSTA, F. A. Contributions of fallow lands in the Brazilian Amazon to $\mathrm{CO}_{2}$ balance, deforestation and the agrarian economy: Inequalities among competing land use. Elementa: Science of the Anthropocene, California University Press, Special Issue, p. 1-23, 2016. Disponível em: $<$ https://www.elementascience.org/articles/10.12952/journal.elementa.000133/>. Acesso em: 29 dez. 2016.

COSTA, F. A. A dinâmica peculiar dos investimentos agrícolas nos Estados Unidos (1948-1994): uma explicação baseadaem eficiência produtiva. EconomiA, v. 8, n. 2, mai./ago. 2007a. 
COSTA, F. A. A relação dos preços na agricultura dos Estados Unidos: uma observacão a partir de abordagem baseada em eficiência reprodutiva. EconomiA, v. 8, n. 1, p.139-159, jan./abr. 2007b.

COSTA, F. A. "Dinâmica agrária na Amazônia, situação reprodutiva e pobreza: uma contextualização estrutural”. In: MIRANDA, C. et al. (Orgs.). A nova cara da pobreza rural: desenvolvimento e a questão regional. 1. ed. Brasília: IICA, v. 17, 2013, p. 111-182,.

COSTA, F. A. Elementos para uma economia política da Amazônia: historicidade, territorialidade, diversidade, sustentabilidade. 1. ed. Belém: Núcleo de Altos Estudos Amazônicos, v. $1,2013 \mathrm{a}$.

COSTA, F. A. Economia camponesa nas fronteiras do capitalismo: teoria e prática nos EUA e na Amazônia Brasileira. Belém: Ed. do NAEA, 2012b.

COSTA, F. A. Trajetórias tecnológicas como objeto de política de conhecimento para a Amazônia: uma metodologia de delineamento. Revista Brasileira de Inovação, v. 8, n. 1, p. 35-86, jan./jun., 2009a.

COSTA, F. A. "Desenvolvimento agrário sustentável na Amazônia: trajetórias tecnológicas, estrutura fundiária e institucionalidade”. In: BECKER, B., COSTA, F. A., COSTA, W. M. Um projeto para a Amazônia no Século 21: desafios e contribuições. 1. ed. Brasília: Centro de Gestão e Estudos Estratégicos, 2009b.

COSTA, F. A. Dinâmica agrária e balanço de carbono na Amazônia. EconomiA, v. 10, n. 1, p. 117-151, jan./mar., 2009c.

COSTA, F. A. O investimento na economia camponesa: considerações teóricas. Revista de Economia Política, v. 15, n. 1, jan./mar. 1995.

COSTA, F. A. et al. "O arranjo produtivo de frutas na regiãopolarizada por Belém do Pará". In: LASTRES, H. M. M., CASSIOLATO, J. E. (Org.) Estratégias para o Desenvolvimento: Um enfoque sobre arranjos produtivos locais do Norte, Nordeste e Centro-Oeste brasileiros. Rio de Janeiro: E-Papers, 2006, p. 67-84.

COSTA, W. M. “A utilização de recursos florestais não-madeireiros”. In: BECKER, B., COSTA, F. A., COSTA, W. M. Um projeto para a Amazônia no Século 21: desafios e contribuições. 1. ed. Brasília: Centro de Gestão e Estudos Estratégicos, 2009, p. 141-194.

DA COSTA, F. S. A dinâmica dos recursos comuns em Unidades de Conservação e Assentamentos Rurais no Amazonas: uma abordagem fuzzy set. Tese (Doutorado em Desenvolvimento Socioambiental) - Programa de Pós-Graduação em Desenvolvimento Sustentável do Trópico Úmido (PDTU), Núcleo de Altos Estudos Amazônicos (NAEA), Universidade Federal do Pará (UFPA), Belém, 2014.

DINIZ, M. B. et al.“A Amazônia (legal) brasileira: evidências de uma condição de armadilha da pobreza”. In: RIVERO, S., JAYME JR., F. G. (Orgs.) As Amazônias do século XXI. Belém: Ed. UFPA, 2008, p. 125-154.

DINIZ, R. E. S. Territorialidade e uso comum entre quilombolas de Santa Rita da Barreira em Contradição com Políticas de Etnodesenvolvimento. Dissertação (Mestrado em Planejamento do Desenvolvimento) - Programa de Pos-Graduação em Desenvolvimento Sustentável do Trópico Úmido (PDTU), Núcleo de Altos Estudos Amazônicos (NAEA), Universidade Federal do Pará (UFPA), Belém, 2011. 
DOSI, G. Technological paradigms and technological trajectories. Revista Brasileira de Inovações, v. 5, n. 1, p. 17-32, jan./jun. 2006.

DRUMOND, J. A. Natureza rica, povos pobres? Questões conceituais e analíticas sobre o papel dos recursos naturais na prosperidade contemporâneas. Ambiente e Sociedade, Ano V, n. 10, 2002.

FIANI, R. Cooperação e Conflito: instituições e desenvolvimento. Rio de Janeiro: Elservier, 2011.

GAYOSO DA COSTA, S. M. Grão na Floresta: Estratégia expansionista do agronegócio na Amazônia. Tese (Doutorado em Desenvolvimento Socioambiental) - Programa de Pos-Graduação em Desenvolvimento Sustentável do Trópico Úmido (PDTU), Núcleo de Altos Estudos Amazônicos (NAEA), Universidade Federal do Pará (UFPA), Belém, 2012.

GRANOVETTER, M.; SWEDBERGER, R. (Orgs). The Sociology of economic life. Philadelphia: Perseus Books, 2011.

GRANOVETTER, M. Economic action and social structure: the problem of embeddedness. American Journal of Sociology, v. 91, n.3, p. 481-510, nov.1985.

GROSSMAN, G. M.; KRUEGER A. B. Environmental impacts of a North American Free Trade Agreement. NBER Working Paper, n. 3914, 1991.

GUMIER COSTA, F. Os Folheiros do Jaborandi: organização, parcerias e seu lugar no extrativismo amazônico. Tese (Doutorado em Desenvolvimento Socioambiental) - Programa de Pos-Graduação em Desenvolvimento Sustentável do Trópico Úmido (PDTU), Núcleo de Altos Estudos Amazônicos (NAEA), Universidade Federal do Pará (UFPA), Belém, 2012.

INCRA - INSTITUTO NACIONAL DE COLONIZAÇÃO E REFORMA AGRÁRIA. Incra nos Estados - Informações gerais sobre os assentamentos da Reforma Agrária. [On-line] Brasília: INCRA, 2016. Disponível em: <http://painel.incra.gov.br/sistemas/index.php>. Acesso em: 29 dez. 2016.

KEMP, R.; SOETE, L. The greening of technological progress. Futures, p. 437 457, jun. 1992.

LUSTOSA, M. C. J. Inovação e tecnologia para uma economia verde: questões fundamentais. Política Ambiental, n. 8, jun. 2011.

MAIA, R. O. M. A política de regularização fundiária e reforma agrária: O PAE nas ilhas do Pará. Dissertação (Mestrado em Planejamento do Desenvolvimento) - Programa de Pos-Graduação em Desenvolvimento Sustentável do Trópico Úmido (PDTU), Núcleo de Altos Estudos Amazônicos (NAEA), Universidade Federal do Pará (UFPA), Belém, 2011.

MARGULIS, S. Causas do desmatamento da Amazônia brasileira. Brasília: Banco Mundial, 2003.

MARIN, I. S. Manejo florestal comunitário em unidades de conservação na Amazônia: uma avaliação de impactos na Resex Verde para Sempres - PA e na RDS Rio Negro - AM. Dissertação (Mestrado em Planejamento do Desenvolvimento) - Programa de Pos-Graduação em Desenvolvimento Sustentável do Trópico Úmido (PDTU), Núcleo de Altos Estudos Amazônicos (NAEA), Universidade Federal do Pará (UFPA), Belém, 2014.

MOURA, E. F. Práticas socioambientais na Reserva de Desenvolvimento Sustentável Mamirauá. Estado do Amazonas, Brasil. Tese (Doutorado em Desenvolvimento Socioambiental) Programa de Pos-Graduação em Desenvolvimento Sustentável do Trópico Úmido (PDTU), 
Núcleo de Altos Estudos Amazônicos (NAEA), Universidade Federal do Pará (UFPA), Belém, 2007.

NOGUEIRA, K. N. S.Camponeses e território em Mocajuba: Uma análise econômico-espacial das trajetórias tecnológicas. Dissertação (Mestrado em Planejamento do Desenvolvimento) - Programa de Pos-Graduação em Desenvolvimento Sustentável do Trópico Úmido (PDTU), Núcleo de Altos Estudos Amazônicos (NAEA), Universidade Federal do Pará (UFPA), Belém, 2015.

NORTH, D. Institutions, institutional change and economic performance.Cambridge: Cambridge University Press, 1990.

NORTH, D.; THOMAS, R. P. The rise of the Western World: a new economic history. Cambridge: Cambridge University Press, 1973.

OLSON, M. The logic of colective action. Public Goods and the Theory of Groups. Cambridge: Harvard University Press, 1965.

OSTROM, E. Governing the commons: the evolution of institutions for collective action. New York: Cambridge University Press, 1990.

OSTROM, E. Rules, games and common-pool resources. Ann Arbor: The University of Michigan Press, 1994.

OSTROM, E.; MCKEAN, M. "Regimes de propriedade comum em florestas: somente uma relíquia do passado?” In: DIEGUES,A. C. MOREIRA, A. C. (Orgs.). Espaços e recursos naturais de uso comum. São Paulo: Nupaub-USP, 2001, p. 79-95.

OSTROM, E.; TUCKER, C. "Pesquisa multidisciplinar relacionando instituições e transformações florestais”. In: MORAN, E.; OSTROM, E. (Orgs.). Ecossistemas florestais: interações homem-ambiente. São Paulo: Editora Senac; Edusp, 2009, p. 109-138.

OSTROM, E. et al.“Teorias subjacentes ao estudo das interações homem-ambiente”. In: MORAN, E.; OSTROM, E. (Orgs.). Ecossistemas florestais: interações homem-ambiente. São Paulo: Editora Senac; Edusp, 2009, p.41-81.

OSTROM. E. Understanding Institutional Diversity. Princenton: Princenton University Press, 2005.

PEARCE, D. et al. Blueprint for a green economy. London: Earthscan, 1989.

POLANYI, K. La gran transformación: las orígenes políticos e económicos de nuestro tiempo. México, DF: Fondo de Cultura, 1992.

PORTER, M. E.; VAN DER LINDE, C. Toward a new conception of the environment-competitiveness relationship. Journal of Economic Perspectives, v. 9, n. 4, p. 97-118, 1995.

SCHNEIDER, R. R. Government and the economy on the Amazon frontier. Washington, DC: The World Bank, 1995.

STEINER, P. A sociologia econômica. São Paulo: Atlas, 2006.

THOMAS, S. Impacto da criação do projeto agroextrativista na gestão participativa dos recursos comuns na várzea amazônica. Tese (Doutorado em Desenvolvimento Socioambiental) Programa de Pos-Graduação em Desenvolvimento Sustentável do Trópico Úmido (PDTU), 
Núcleo de Altos Estudos Amazônicos (NAEA), Universidade Federal do Pará (UFPA), Belém, 2014.

UNEP - UNITED NATIONS ENVIRONMENT PROGRAMME. Towards a green economy: pathways to sustainable development and poverty errradication. Washington, DC: UNEP, 2011.

WILLIAMSON, O. Markets and hierarchies: analysis and antitrust implications. New York: The Free Press, 1975.

WILLIAMSON, O. Transaction-cost economics: the governance of contractual relations. Journal of Law and Economics, v. 22, Oct. 1979.

WILLIAMSON, O. The Mechanism of Governance. Oxford University Press, New York, 1996.

WORLD BANK. Green Growth Report. Washington, DC: World Bank, 2012. 